\title{
Phytochemistry, Pharmacological Activities and Intellectual Property Landscape of Gardenia jasminoides Ellis: a Review
}

\author{
Rohan Sharadanand Phatak*
}

Directorate of Research, Krishna Institute of Medical Sciences Deemed University, Malkapur, Karad, Maharashtra, India.

\begin{abstract}
Gardenia jasminoides, the genus of Gardenia, a Chinese medicinal plant, which belongs to the family Rubiaceae is herb used since ancient times. It is also known as Fructus Gardeniae and Gardenia augusta as different synonyms, well known as Anant in Marathi language, Gandharaj in Hindi language and $\mathrm{Zhi} \mathrm{Zi}$ in Chinese language. Gardenia jasminoides extracts and its main active phytoconstituents geniposide, genipin, crocin, crocetin have been reported for a wide range of pharmacological activities such as anti-hyperglycemic, anti-atherosclerotic, anti-inflammatory, anti-arthritis, anti-cancer, anti-apoptotic, anti-oxidant, anti-angiogenic, anti-thrombotic, anti-microbial and miscellaneous activities. Also it has been explored its protective effect through diverse mechanisms like neuroprotective for Alzheimer's disease, hepatoprotective, gastro-protective, retino-protective, nephro-protective, skin protective activities. This review will give new insights of Gardenia jasminoides relating to the ethnopharmacology, phytochemistry and pharmacological uses. This data will also highlight the patenting trends and different assignees involved in filing patents for Gardenia jasminoides.
\end{abstract}

Key words: Anant, Crocin, Crocetin, Fructus Gardeniae, Gardenia jasminoides, Gardenia augusta, Gandharaj, Geniposide, Genipin.

\section{SUMMARY}

- A number of phytochemicals isolated from Gardenia jasminoides Ellis in the structural characterization studies have been reported. Out of them, geniposide, genipin, crocin, crocetin are found as pharmacologically active principle. Geniposide is the major phytochemical extensively used in studies among all phytoconstituents.

- Gardenia jasminoides has been explored in a wide range of pharmacological activities such as anti-hyperglycemic, anti-atherosclerotic, anti-inflammatory, anti-arthritis, anti-cancer, anti-apoptotic, anti-oxidant, anti-angiogenic, antithrombotic, anti-microbial and miscellaneous activities. Its anti-inflammatory activity has been reported in the topmost rank.
- Out of these assignees, China is the main leading country to be assignee for filing highest number of patents for Gardenia jasminoides in the field of traditional Chinese medicine. In the year of 2014, patents for Gardenia jasminoides has been filed in the highest record.

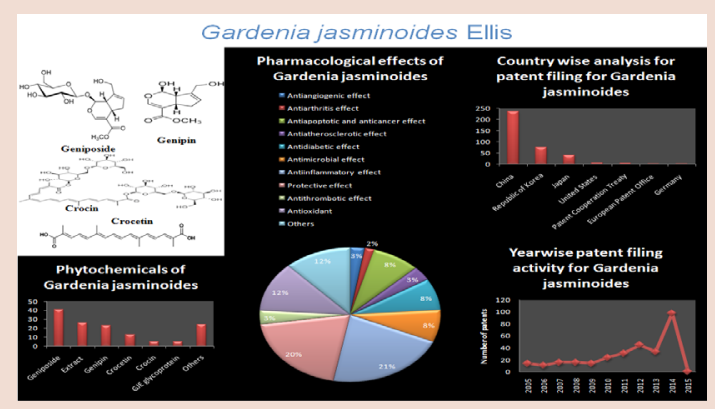

PICTORIAL ABSTRACT

Abbreviations used: GJ: Gardenia jasminoides Ellis, FG: Fructus Gardeniae, TCM: Traditional Chinese Medicine, AD; Alzheimer's disease, WIPO : World Intellectual Property Organization, AP: Acute Pancreatitis, IDE: Insulin Degrading Enzyme, PPAR: Peroxisomal Proliferator-Activated Receptor, ROS: Reactive Oxygen Species.

\section{Correspondence:}

Mr. Rohan Sharadanand Phatak, Junior Research Officer, Directorate of Research, Krishna Institute of Medical Sciences Deemed University, Malkapur, Karad-415539, Maharashtra, India.

Email: phatak.rohan1983@gmail.com

DOI : 10.5530/pj.2015.5.1

\section{INTRODUCTION}

\section{Ethnopharmacology}

Gardenia jasminoides Ellis (GJ), the genus of Gardenia which is belonging to the family Rubiaceae, an ancient medical herb, is noted for its medicinal properties in Chinese, Korean, pharmacopoeias. It is also known as Fructus Gardeniae and Gardenia augusta as different synonyms, well known as Anant in Marathi language; Gandharaj in Hindi language and $\mathrm{Zhi} \mathrm{Zi}$ in Chinese language. Gardenia jasminoides, gardenia, cape jessamine, danh-danh, or jasmin is an evergreen flowering plant. Its origin is found in most Asian continents like Vietnam, Southern China, Taiwan, Japan, Myanmar and India. It is growing wild and also cultivated in garden in warm temperate and subtropical climates. It has heavily fragrant white summer flowers with its shiny green leaves. Traditionally the fruit of Gardenia jasminoides has been used in formulating folk medicine in treating inflammation, headache, edema, fever, hepatic disorders, and hypertension. ${ }^{1}$ It is well known as Fructus Gardeniae (FG), namely the dried ripe fruits of G. jasminoides, has reported for its extensive pharmacological activities and widely used in Traditional Chinese Medicine (TCM). ${ }^{2}$ Parmar et $a l^{3}$ have been well documented the review of this plant species having various medicinal properties in 2000 however fur- ther reviewing of this plant species especially on Gardenia jasminoides has not been reported so far.

\section{Literature survey and search strategies for patent applications}

The aim of this study was to review the different pharmacological activities and to reveal newer phytoconstituents in Gardenia jasminoides through survey of several literatures. We have investigated scientific literature survey by applying search strategies "Gardenia jasminoides Ellis", "Gardenia jasminoides", "Fructus Gardeniae", "Gardenia jasminoides Extract” in the databases like PubMed, @sciencedirect, and Google scholar. Patent related information of Gardenia jasminoides was searched by using various databases such as @espacenet and WIPO.

\section{Phytochemistry}

Geniposide, genipin, geniposidic acid, crocin and crocetin are major phytoconstituents of Gardenia jasminoides which have been used exten- 


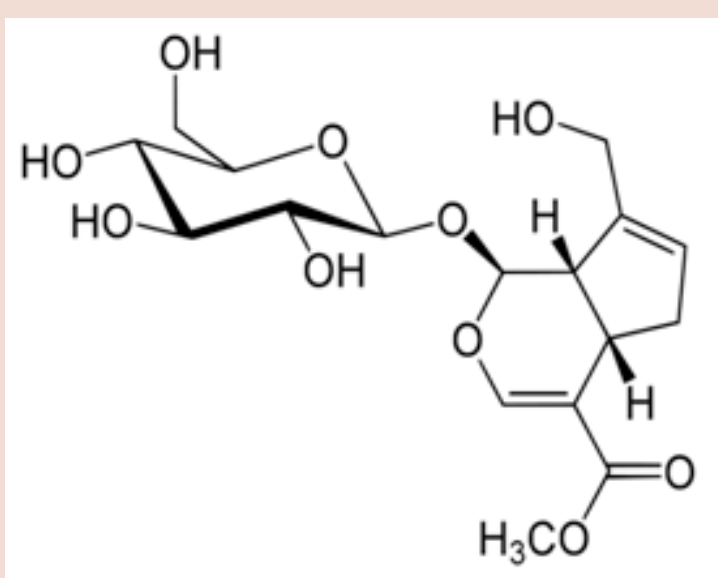

Figure 1: Structure of Geniposide

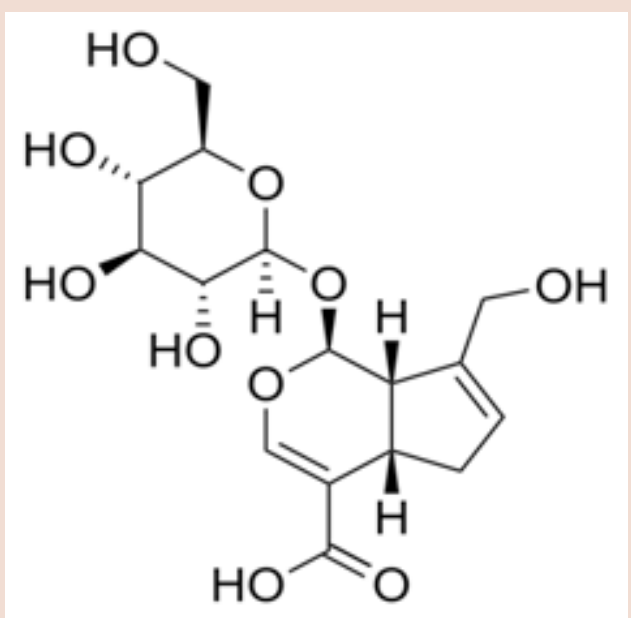

Figure 3: Structure of Geniposidic acid

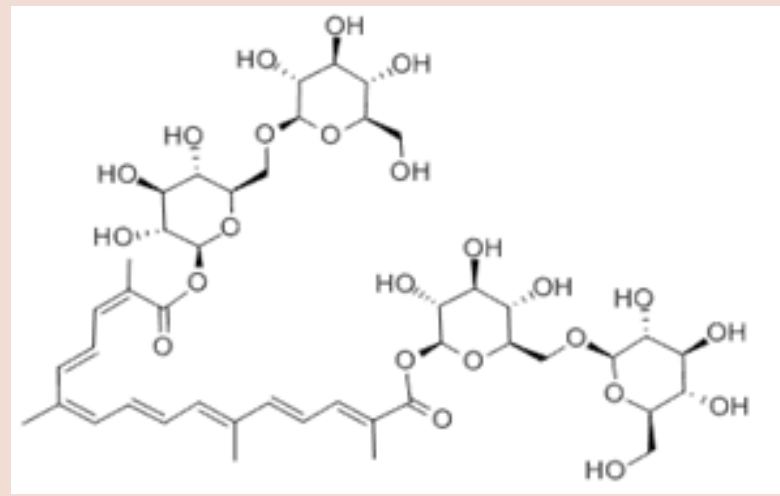

Figure 5: Structure of Crocin

sively in the phytochemical analysis and pharmacological studies (Figure 1-5). A number of newer phytochemicals have been isolated and many of them have been reported for anti-cancer, anti-inflammatory, antioxidant, anti-viral, anti-bacterial, anti-depressant, neuroprotective, antiprotozoal, useful for treatment of ankle sprain, osteoporosis and melanogenesis inhibitory effect as shown in Table 1.

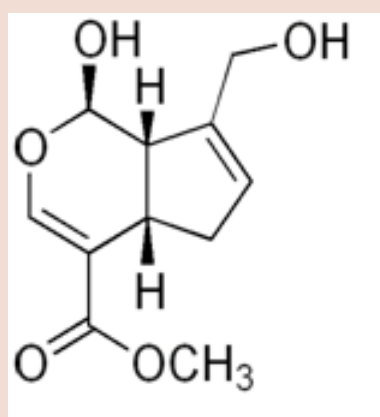

Figure 2: Structure of Genipin<smiles>CC(/C=C/C=C(\C)C(=O)O)=C\C=C\C=C(C)\C=C\C=C(/C)C(=O)O</smiles>

Figure 4: Structure of Crocetin

\section{Pharmacological activities}

Gardenia jasminoides has been used for treatment of inflammation, folklore cure for different ailments, in the ancient traditional medicine system. Figure 6 depicts the overall scenario of the pharmacological activities of different phytoconstituents isolated from Gardenia jasminoides. Figure 7 overviews the pharmacological activities of Gardenia jasminoides.

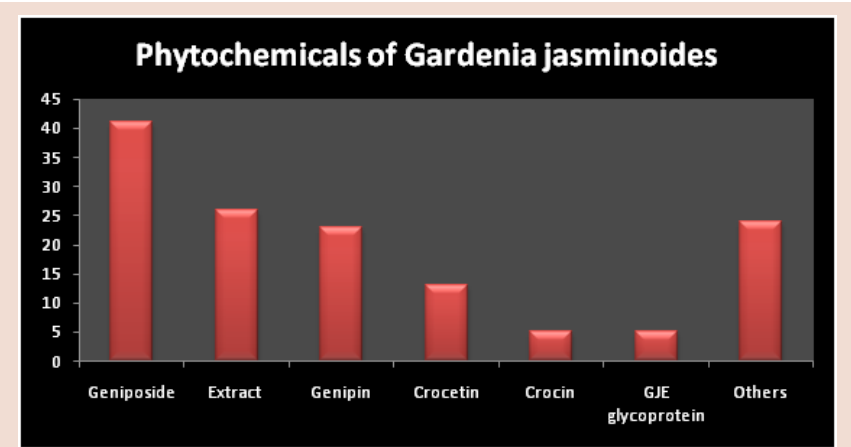

Figure 6: Pharmacological activities of different phytoconstituents isolated from Gardeniajasminoides 
Table 1: Shows the different phytochemicals isolated from Gardenia jasminoides Ellis

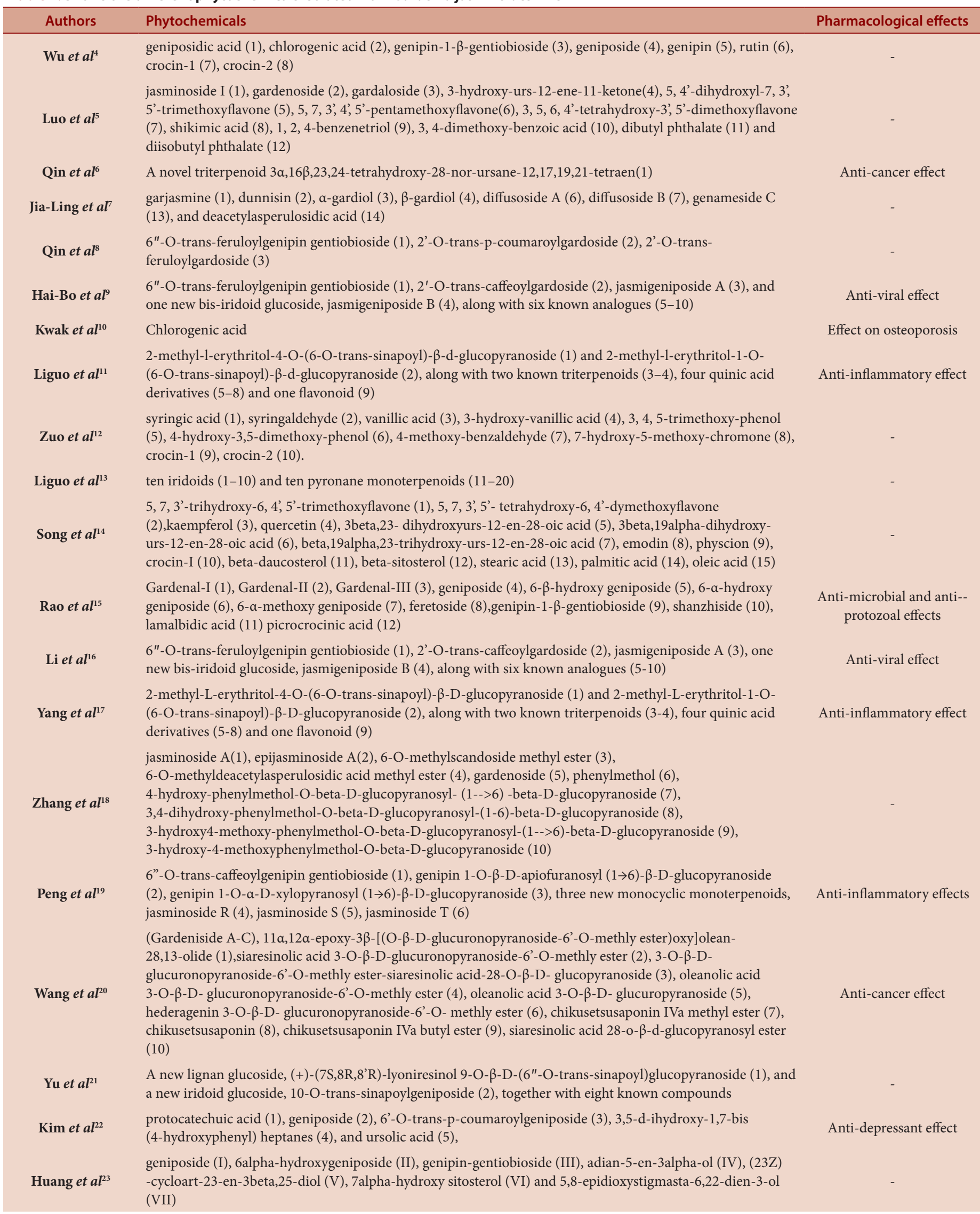




\begin{tabular}{|c|c|c|}
\hline Akihisa et $a l^{24}$ & $\begin{array}{l}\text { 10-O-(4"-O-methylsuccinoyl)geniposide (7), and two new pyronane glycosides, jasminosides } \mathrm{Q} \text { and } \mathrm{R}(13 \text { and } \\
\text { 14, resp.), along with nine known iridoid glycosides, } 1-6 \text { and 8-10, and two known pyronane glycosides, } 11 \\
\text { and } 12\end{array}$ & $\begin{array}{l}\text { Melanogenesis inhibitory } \\
\text { effect }\end{array}$ \\
\hline Yu et $a l^{25}$ & $\begin{array}{l}\text { (1R,7R,10S)-11-O- } \beta \text {-D-glucopyranosyl-4-guaien-3-one (1) and (1R,7R,10S)-7-hydroxy-11-O- } \beta \text {-D- } \\
\text { glucopyranosyl-4-guaien-3-one ( } 2 \text { ) }\end{array}$ & - \\
\hline Clifford et $a l^{26}$ & $\begin{array}{l}\text { three caffeoylquinic acids, three dicaffeoylquinic acids, three sinapoylquinic acids, four caffeoyl-sinapoylquinic } \\
\text { acids, two feruloyl-sinapoylquinic acids, one p-coumaroyl-sinapoylquinic acid, three (3-hydroxy, 3-methyl) } \\
\text { glutaroylquinic acids, two (3-hydroxy, 3-methyl) glutaroyl-feruloylquinic acids, one (3-hydroxy, 3-methyl) } \\
\text { glutaroyl-dicaffeoylquinic acid, and one (3-hydroxy, 3-methyl) glutaroyl-caffeoyl-feruloylquinic acid. } \\
\text { Six (3-hydroxy, 3-methyl) glutaroyl-caffeoylquinic acids were detected and two were tentatively assigned } \\
\text { as 3-caffeoyl-4-(3-hydroxy, 3-methyl) glutaroylquinic acid and 3-caffeoyl-5-(3-hydroxy, 3-methyl) } \\
\text { glutaroylquinic acid. }\end{array}$ & - \\
\hline Jarubol et $a l^{27}$ & Linalool, alpha-farnesene, $\mathrm{z}$-3-hexenyl tiglate and trans-beta-ocimene & $\begin{array}{l}\text { Anti-microbial and anti- } \\
\text { oxidant effect }\end{array}$ \\
\hline Chen et $\mathrm{l}^{28}$ & $\begin{array}{l}\text { genipin 1-O-beta-D-isomaltoside (1) and genipin 1,10-di-O-beta-D-glucopyranoside (2), together with six } \\
\text { known iridoid glycosides, genipin 1-O-beta-D-gentiobioside (3), geniposide (4), scandoside methyl ester } \\
\text { (5), deacetylasperulosidic acid methyl ester (6), 6-O-methyldeacetylasperulosidic acid methyl ester (7), and } \\
\text { gardenoside (8) }\end{array}$ & Treatment of ankle sprain. \\
\hline Yu et al ${ }^{29}$ & $\begin{array}{l}\text { 6"-O-trans-sinapoylgenipin gentiobioside (1), 6"-O-trans-p-coumaroylgenipin gentiobioside (2), } \\
\text { 6"-O-trans-cinnamoylgenipin gentiobioside (3), 6'-O-trans-p-coumaroylgeniposide (4), 6'-O-trans- } \\
\text { p-coumaroylgeniposidic acid (5), 10-O-succinoylgeniposide (6), and 6'-O-acetylgeniposide (7), two } \\
\text { new monoterpenoids, 11-(6-O-trans-inapoylglucopyranosyl) gardendiol (8) and 10-(6-O-trans- } \\
\text { sinapoylglucopyranosyl) gardendiol (9), and three known ones, 6'-O-trans-sinapoylgeniposide (10), } \\
\text { geniposide (11), and 10-O-acetylgeniposide (12), }\end{array}$ & $\begin{array}{l}\text { Neuroprotective effect on } \\
\text { Alzheimer's disease. }\end{array}$ \\
\hline Li et $a l^{30}$ & gardenia oil & $\begin{array}{l}\text { Hypnotic and anti--seizure } \\
\text { effects }\end{array}$ \\
\hline Chen $e a^{31}$ & $\begin{array}{l}\text { jasminodiol (1), jasminoside H (6), 6'-O-sinapoyljasminoside A (7), 6'-O-sinapoyljasminoside C (8), and } \\
\text { jasminoside I (9) }\end{array}$ & Anti-inflammatory effect \\
\hline Chen et $\mathrm{l}^{32}$ & $\begin{array}{l}\text { imperatorin (1), isoimperatorin (2), crocetin (3), 5-hydroxy-7, 3, 4, 5'-tetrainethoxyflavone (4), 2-methyl-3, } \\
\text { 5-dihydroxychromone (5), sudan III (6), geniposide (7), crocin (8), crocin-3 (9) }\end{array}$ & - \\
\hline Kim et $a^{33}$ & $\begin{array}{l}\text { vanillic acid 4-O-beta-d-(6'-sinapoyl) glucopyranoside (1) and five new quinic acid derivatives, methyl } \\
\text { 5-O-caffeoyl-3-O-sinapoylquinate (2), ethyl 5-O-caffeoyl-3-O-sinapoylquinate (3), methyl 5-O-caffeoyl-4- } \\
\text { O-sinapoylquinate (4), ethyl 5-O-caffeoyl-4-O-sinapoylquinate (5), and methyl 3,5-di-O-caffeoyl-4-O-(3- } \\
\text { hydroxy-3-methyl) glutaroylquinate (6) }\end{array}$ & $\begin{array}{l}\text { Anti-oxidant effect, anti- } \\
\text { viral effect }\end{array}$ \\
\hline Chang et $a l^{34}$ & $\begin{array}{l}\text { gardaloside (1), jasminoside G (2), geniposide (3), 6alpha-hydroxygeniposide (5), ixoroside (7), and } \\
\text { shanzhiside (8) }\end{array}$ & Immunosuppressive effect \\
\hline Machida et $\mathbf{l}^{35}$ & $\begin{array}{l}7 \text { beta, } 8 \text { beta-epoxy- } 8 \text { alpha-dihydrogeniposide (1) 8-epiapodantheroside (2), were isolated, together with six } \\
\text { known (3-8) and three artifact ( } 9 \text {-11) iridoids }\end{array}$ & - \\
\hline Machida et $a l^{36}$ & $\begin{array}{l}\text { gardenate A (1), 2-hydroxyethyl gardenamide A (2), (1R,7R,8S,10R)-7,8,11-trihydroxyguai-4-en-3-one } \\
\text { 8-O-beta-D-glucopyranoside (3) and Jasminoside F (4) }\end{array}$ & - \\
\hline
\end{tabular}

\section{Anti-diabetic and anti-atherosclerotic activities}

Aqueous extract of Gardenia jasminoides in normal dose $200 \mathrm{mg} / \mathrm{kg}$ exerted a PPAR $\gamma$-activating hypoglycemic effect by restoring insulin resistance therefore; it was proved as a potential agent for insulin-sensitizing in type 2 diabetes mellitus with insulin resistance ${ }^{37}$ and also attenuated the severity of acute pancreatitis (AP) as well as pancreatitis-associated lung injury. ${ }^{38}$ The main mechanism of hypoglycemic effect of geniposide was mediated by inhibiting the GP and G6Pase activities. ${ }^{39}$ The fibril precursors of islet amyloid polypeptide (IAPP) are cytotoxic to pancreatic $\beta$ cells which lead to $\beta$-cell dysfunction in type 2 diabetes mellitus (T2DM). The protective effects of geniposide exerted in pancreatic INS-1E cells by preventing human islet amyloid polypeptide (hIAPP)-induced cell damage in INS-1E cells and bacitracin, an inhibitor of IDE activity and involving up regulation of IDE expression a key degrading protein of (hIAPP).$^{40}$ Geniposide inhibited the phosphorylation of downstream target GSK3 $\beta$ which was counteracted by preincubation with LY294002 along with increased expression of GLUT2 ${ }^{41}$ and restraining the adhesion of monocytes to HUVECs and the expression of CAMs induced by high glucose in treatment for diabetic vascular injury. ${ }^{42}$ Ethanolic extract of Gardenia jasminoides inhibited TNF-alpha-induced NF-kappaB activa- tion, adhesion molecule expression, and monocyte-endothelial interaction in the mechanism of treating vascular diseases, such as atherosclerosis. ${ }^{43}$ Geniposide up-regulated the expression of foxp3, promoted Treg-cell-associated cytokines (TGF- $\beta 1$ and IL-10) cells and ameliorated the atherosclerotic lesions progression partly through lipids regulation and immunoregulation ${ }^{44}$ while its metabolite genipin suppressed the intracellular lipid accumulation and also significantly increased the intracellular expression of a fatty acid oxidation-related gene (peroxisomal proliferator-activated receptor: PPARa) so it was confirmed its anti-obesity, insulin resistance-alleviating and abnormal lipid metabolismalleviating effects. ${ }^{45}$ Effects of geniposidic acid on protecting vascular endothelium and reversing plaque formation was elevated. ${ }^{46}$ Genipin exerted anti-diabetic activity by improving insulin sensitivity through ameliorating insulin-stimulated glucose update and glycogen synthesis, inhibited overproduction of cellular reactive oxygen species (ROS); reversing hepatic oxidative stress-associated JNK hyperactivation and reduced Akt phosphorylation and alleviating mitochondrial membrane potential (MMP) and mitochondrial ATP dysfunction ${ }^{47}$ promoted glucose transporter 4 (GLUT4) translocation to the cell surface in sub-cellular membrane fraction and amplified the phosphorylation of insulin 


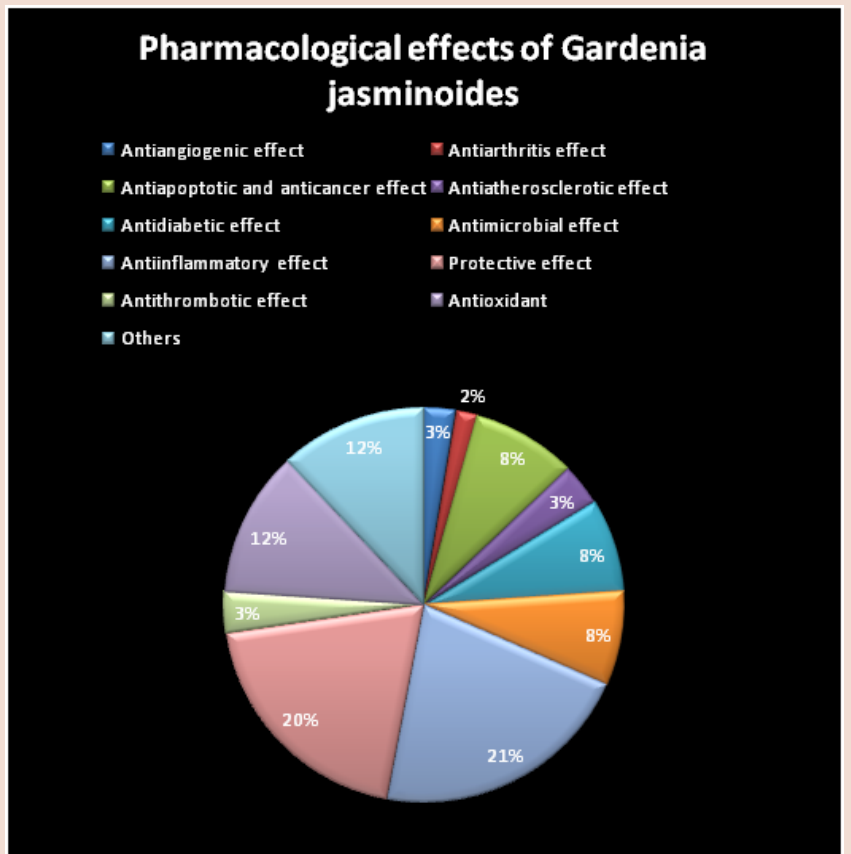

Figure 7: Overview of pharmacological activities of Gardenia jasminoides in scientific literature analysis Source: WIPO Patent analysis

receptor substrate-1 (IRS-1), AKT, and GSK3 $\beta$ to augment ATP levels, closed K (ATP) channels, the concentration of calcium in the cytoplasm in $\mathrm{C}(2) \mathrm{C}(12)$ myotubes with increases the level of ROS and ATP in myotubes. ${ }^{48}$ Crocetin proved its anti-diabetic effect by restoring dexamethasone-induced insulin resistance and related abnormalities in rats ${ }^{49}$ by inhibiting pancreatic lipase $\mathrm{s}^{50}$ and malabsorption of fat and cholesterol due to the inhibition of pancreatic lipase and its metabolite, crocetin improved hyperlipidemia. ${ }^{51}$

\section{Anti-inflammatory activity}

Geniposide markedly inhibited the lipopolysaccharide (LPS)-induced tumor necrosis factor- $\alpha$ (TNF- $\alpha$ ), IL- 6 and IL-1 $\beta$ production both in vitro as well as in vivo. It neutralizes in vitro LPS through binding with LPS which significantly protected sepsis model mice ${ }^{52}$ and significantly reduced the infiltration of inflammatory cells and down regulated the production of tumor necrosis factor- $\alpha$ (TNF- $\alpha$ ), interleukin-1 $\beta$ (IL$1 \beta$ ), and interleukin-6 (IL-6) by suppressing the phosphorylation of inhibitory kappa B (I $\kappa \mathrm{B} \alpha)$, nuclear factor- $\kappa \mathrm{B}(\mathrm{NF}-\kappa \mathrm{B}), \mathrm{p} 38$, extracellular signal-regulated kinase (ERK), and $c$-Jun N-terminal kinase (JNK). ${ }^{53}$ Furthermore, it is not only down-regulating the expression of TLR4 up-regulated by LPS stimulated primary mouse macrophages but also LPS-induced IL-8 production in HEK293-mTLR4/MD-2 cells. It attenuated lung histopathologic changes in the mouse models in vivo which indicated for to be highly effective in inhibiting acute lung injury. ${ }^{54}$ Antiinflammatory effect of geniposide exerted by inducing the production of ROS and inducible nitric oxide synthase (iNOS) in lipopolysaccharide (LPS)-stimulated N9 murine microglial cells through the p38, ERK1/2 and nuclear factor- $\mathrm{KB}(\mathrm{NF}-\mathrm{\kappa B})$ signaling pathways; attenuating the activation of N9 cells; inhibiting the overproduction of NO, intracellular ROS and the expression of iNOS induced by LPS in the cells and blocking the phosphorylation of p38, ERK1/2 and inhibited the drop-off of I $\kappa$ B induced by LPS in the cells. ${ }^{55}$ Also geniposide acts as anti-asthmatic agent due to its anti-inflammatory properties which prevented eosinophilic pulmonary infiltration, attenuated the increases in interleukin (IL)-4, IL-5, and IL-13, and reduced eotaxin and vascular cell adhesion molecule 1 (VCAM-1) expression. ${ }^{56}$ It substanti-ally inhibited LPSinduced alveolar wall changes, alveolar haemorrhage, and neutrophil infiltration in lung tissue, with evidence of reduced myeloperoxidase (MPO) activity by blocking nuclear factor-kappaB (NF- $\kappa \mathrm{B})$ and mitogen-activated protein kinases (MAPK) signaling pathway activation. ${ }^{57}$ It mainly exerts its anti-inflammatory effects through suppressing the expression mitogen-activated protein kinase (MAPK), activator protein (AP)-1and release of the LPS-induced production of the inflammatory factors such as cytokine, tumor necrosis factor- $\alpha$ (TNF- $\alpha$ ) and interleukin-6 (IL-6), nitric oxide (NO) and prostaglandin E2 (PGE2), the mRNA and protein expression of the NO and PGE2 synthases, inducible nitric oxide synthase (iNOS) and cyclooxygenase-2 (COX-2). ${ }^{58}$ It facilitates to restructure the ligament tears by proliferating ligament fibroblasts and promoting the synthesis of collagen in case of ankle sprain..$^{59}$ Genipin exhibited anti-inflammatory effects via downregulation of chemokine ligand, chemokine receptor, and IFN-induced protein productions in LPS-induced acute systemic inflammation. ${ }^{60}$ Genipin prevented IL- $1 \beta$ mediated CCL20 and IL- 6 production in HPDLCs through suppressing nuclear factor kappa $B(\mathrm{NF}-\kappa \mathrm{B})$ p65, extracellular signal regulated kinase (ERK) and MAPK/ERK kinase (MEK) phosphorylations. ${ }^{61}$ Both genipin and geniposide inhibited production of exudate and nitric oxide (NO). However, genipin possessed stronger anti-inflammatory activity than geniposide. ${ }^{1}$ Genipin increased production of the ROS and the ROS-producing NAPDH-oxidase (NOX) family oxidases, NOX2 and NOX3 by activating Akt, MAPKs and AP-1/NF- $\kappa B$ for ROS-dependent cyclooxygenase-2 (COX-2) expression up-regulation and prostaglandin E2 (PGE2) production. ${ }^{62}$ It attenuates lipopolysaccharide (LPS)-induced sickness behavior in rodents due to changes of emotional behaviors through inhibition of neural activation and inflammatory responses in the paraventricular nucleus (PVN) of the hypothalamus and the central nucleus of the amygdala (CeA). ${ }^{63}$ Anti-NO production and anti-inflammatory activities of Gardenia jasminoides were increased by suppression of the protein and m-RNA expressions of iNOS and COX-2 in LPS-activated macrophage and concluded that crocetin has greater anti-inflammatory activity than crocin. ${ }^{64}$ Crocin markedly exerted the expression of heme oxygenase-1 (HO-1) leading to anti-inflammatory response by inhibiting inducible nitric oxide synthase (iNOS) expression and nitric oxide production via downregulation of nuclear factor kappa B activity in lipopolysaccharide (LPS) stimulated RAW 264.7 macrophages and inducing $\mathrm{Ca}(2+)$ mobilization from intracellular pools and phosphorylation of $\mathrm{Ca}(2+) /$ calmodulin-dependent protein kinase 4 (CAMK4). ${ }^{65}$ Crocin was found to inhibit the productions of prostaglandin E (2) (PGE (2)) in lipopolysaccharide (LPS)-challenged RAW 264.7 significantly, which is similar to its prevention of the nuclear translocation of the NFkappaB p50 and p65 subunits. ${ }^{66}$ Crocetin reduced the LPS-induced lung oedema and histological changes by increasing LPS-impaired superoxide dismutase (SOD) activity, and decreased lung myeloperoxidase (MPO) activity by significantly attenuating LPS-induced mRNA and protein expression of interleukin-6 (IL-6), macrophage chemoattractant protein-1 (MCP-1), and tumor necrosis factor- $\alpha$ (TNF- $\alpha$ ) in lung tissue. ${ }^{67}$

Gardenia jasminoides Ellis (GJE) has been used to cure inflammation in Korean folk medicine for a long time. Inhibitory effect of glycoprotein isolated from GJE $(10 \mathrm{mg} / \mathrm{kg}, 27 \mathrm{kDa})$ was effective on inflammation mechanism in cadmium chloride-exposed ICR mice by decreasing the levels of lactate dehydrogenase (LDH), alanine aminotransferase (ALT), and thiobarbituric acid-reactive substances (TBARS); attenuating c-Jun Nterminal protein kinase (JNK), heat shock protein 27 (Hsp27), activator protein (AP)-1, nuclear factor (NF)- $\mathrm{kB}$ and expression of inflammationrelated mediators including pro-inflammatory cytokines tumor necrosis factor (TNF)- $\alpha$ and interleukin (IL)- 6 with increased activities of anti-oxidative enzymes viz; superoxide dismutase (SOD), gluthathione peroxidase $(\mathrm{GPx})^{68}$ and also suppressing intracellular ROS and intracellular 
$\mathrm{Ca}\left(2^{+}\right)$, activities of activator protein (AP)- 1 , cyclooxygenase (COX)-2, matrix metalloproteinase (MMP)-9, and arachidonic acid (AA). ${ }^{68}$

\section{Protective effects}

\section{Neuroprotective activity for Alzheimer's disease (AD)}

Microglia is the prime effectors in immune and inflammatory responses of the central nervous system (CNS). Brains of Alzheimer's disease (AD) patients are characterized by large deposits of amyloid beta peptide (Abeta). Abeta responsible to increase free radical production in nerve cells, leading to cell death that is characterized by lipid peroxidation, DNA/ RNA and protein oxidation. Ethanolic extract of Gardenia jasminoides was effective significantly among hexane, chloroform, and ethyl acetate to ameliorate on Abeta-induced oxidative stress, by reducing oxidative stress. ${ }^{69}$ Oxidative stress and mitochondrial dysfunction contribute to the disease progression in Alzheimer's disease (AD) which geniposide exerts protective effects on mitochondrial dysfunction in APP/PS1 mice through suppressing the mitochondrial oxidative damage to attenuate memory deficits and increasing the mitochondrial membrane potential and activity of cytochrome $\mathrm{c}$ oxidase through the suppression of mitochondrial oxidative stress. Thus, geniposide regarded to be a potential therapeutic reagent for halting and preventing $\mathrm{AD}$ progress. ${ }^{70}$ Geniposide showed a $22.8 \%$ acetyl cholinesterase (AChE) inhibitory activity and a potent ameliorating effect on scopolamine-induced memory impairment in amnesic mice of $93.4 \%$ as compared to the control group. ${ }^{71}$ It has protection to neuronal cells from damage in oxygen-glucose deprived hippocampal slice culture, the granule cell layer than on the pyramidal cell layer including CA 1 and CA $3 .^{72}$ Receptor for advanced glycation end products (RAGE) mediated $A \beta$-induced microglial activation leads to neuroinflammation through release of proinflammatory mediators such as tumor necrosis factor- $\alpha$ (TNF- $\alpha$ ), interleukin- $1 \beta$ (IL- $1 \beta)$. So it was proved to be a potent suppressor of neuroflammation by blocking significantly $A \beta$-induced RAGE-dependent signaling (activation of ERK and NF- $\mathrm{kB}$ ) along with the production of TNF- $\alpha$ and IL- $1 \beta$ in cultured BV2 microglia cells $;^{73}$ by attenuating the oligomeric $A \beta(1-42)$-induced inflammatory response by blocking the ligation of $A \beta$ to receptor for advanced glycation end products (RAGE); suppressing the RAGE-mediated signaling in vitro while the production of tumor necrosis factor- $\alpha$ (TNF- $\alpha$ ) and interleukin- $1 \beta$ (IL-1 $\beta$ ) and cerebral $A \beta$ accumulation in vivo. Furthermore, geniposide augments synaptic plasticity by attenuating the $\mathrm{A} \beta$-induced reduction of long-term potentiation and increasing the miniature excitatory postsynaptic current (mEPSC) amplitude and frequency in hippocampal neurons. ${ }^{74}$ Neuroprotective potential of genipin exerted against hepatic damage from ROS and RNS production in organotypic hippocampal slice cultures (OHSC) by reducing $\mathrm{S}$-nitroso-N-acetylpenicillamine (SNAP) induced cell death and nitrite to lower level. ${ }^{75}$ Genipin repressed brain microglial activation effectively inhibiting LPS-induced nitric oxide (NO) release from cultured rat brain microglial cells as well as microglia stimulated with interferon-gamma and amyloid-beta; in turn to attenuate the release of tumor necrosis factor-alpha, interleukin-1beta, prostaglandin $\mathrm{E}(2)$, intracellular reactive oxygen species, and NF-kappaB activation. ${ }^{76}$ Genipin induced neurite outgrowth in PC12h and protected Neuro 2a cells in rat primary hippocampal neurons from beta-amyloid peptide, serum deprivation, oxidative stress and through suppressing A23187 (calcium ionophore)induced transcription of immunoglobulin-binding protein/glucoseregulated protein of $78 \mathrm{kDa}(\mathrm{BiP} / \mathrm{GRP78})$ protein, an endoplasmic reticulum (ER) stress marker protein and A23187-induced cytotoxicity in turn which significantly activated caspase $3 / 7$, as mediator of apoptosis, A23187. Therefore, genipin prevented neurodegeneration in Alzheimer's disease and Parkinson's disease involving ER stress. ${ }^{77}$ Crocin and crocetin were effective in the inhibition of LPS-induced neurotoxic molecules like NF- $\kappa B$ activation, nitric oxide (NO) release from microglia, tumor necrosis factor- $\alpha$, interleukin- $1 \beta$, and intracellular reactive oxygen species from cultured rat brain microglial cells. ${ }^{78}$

\section{Hepatoprotective activity}

Gardenia jasminoides extract significantly reduced liver mRNA and/ or protein expression of transforming growth factor $\beta 1$ (TGF- $\beta 1$ ), collagen type I ( $\mathrm{Col} \mathrm{I}$ ) and $\alpha$-smooth muscle actin ( $\alpha$-SMA) by suppressing the upregulation of TGF- $\beta 1$, Col I and $\alpha$-SMA in LX-2 exposed to recombinant TGF- $\beta 1$ and Smad 2 phosphorylation in LX-2 cells. ${ }^{79}$ Strong inhibitory action of Gardenia jasminoides extract on lipidosis and inflammatory injury in the rat model by enhancing serum ALT and AST activities, and expression of TNF-alpha and P-IkB proteins in liver tissue significantly led to inhibition of the free fatty acid metabolism pathway. ${ }^{79}$ Hepatoprotective role of geniposide was initiated to acute alcoholic liver injury via up-regulating the expression of the main anti-oxidant enzymes. ${ }^{80}$ Geniposide and genipin protected significantly to liver by potentiating increased hepatic heme oxygenase-1 protein expression; attenuating increased levels of $\mathrm{tBid}$, Cytochrome $\mathrm{C}$ protein expression, caspase- 3 activity; and reducing increased apoptotic cells in the hepatic ischemia/reperfusion (I/R) injured mice ${ }^{81}$ Glycine N-methyltransferase (GNMT) and glycogen phosphorylase (PYGL) were preferred for novel biomarker for hepatic injuries rather than convenient liver biomarkers. ${ }^{82}$ Genipin increased hepatoprotectin markedly against d-galactosamine/ lipopolysaccharides (GalN/LPS) induced hepatic damage related with its anti-oxidative, anti-apoptotic activities, and inhibition of NF-kappaB nuclear translocation and nuclear p-c-Jun expression. ${ }^{83}$ Hepatoprotective effects of geniposidic acid alleviated GalN/LPS-induced liver injury through enhancing anti-oxidative defense system and involving apoptotic signaling pathways which was analogous to that of genipin. ${ }^{81}$ Crocetin significantly restored the endothelium-dependent relaxation (EDR) of thoracic aorta by enhancing the vessel eNOS activity to lead the elevation of NO production. ${ }^{84}$ GJE glycoprotein explored an inhibitory effect on glucose/glucose oxidase (G/GO)-induced cytotoxicity and intracellular reactive oxygen species production by blocking lactate dehydrogenase release; increasing nitric oxide production; activation of anti-oxidant enzymes accompanied by the inhibition of the cytotoxic-related signals hepatic cytochrome c, nuclear factor-kappaB and activator protein-1. In the way, GJE glycoprotein could ameliorate the liver function owing to its hepatoprotective and hypolipidaemic properties. ${ }^{72}$

\section{Gastro-protective activity}

Ethanolic extract of Gardenia jasminoides Ellis (GJE extract), exhibited potential anti-gastric diseases activity, such as gastritis and gastric cancer due to free radical scavenging activities Ursolic acid and crocin showed acid-neutralizing property by less inhibition of $\mathrm{NaOH}$ consumption amount whereas genipin inhibited approximately of $\mathrm{HCl}$-ethanol induced gastric lesion in rats. ${ }^{85}$ GJE extract, ursolic acid and genipin showed the acid-neutralizing capacities and inhibitory effects on the growth of Helicobacter pylori (H. pylori) in which the GJE extract and ursolic acid had cytotoxic activity against AGS and SUN638 gastric cancer cells while genipin and ursolic acid inhibited significant $97.1 \% \mathrm{HCl} /$ ethanol-induced gastric lesions. ${ }^{86}$

\section{Skin protective activity}

Gardenia jasminoides extract (GJE) and its ethyl acetate fraction Gardenia jasminoides extract (GJE-EA) inhibited compound 48/80-induced histamine release from MC/9 mast cells. Topical application of GJE or GJE-EA to dermatophagoides farinae-exposed NC/Nga mice reduced the symptoms of atopic dermatitis (AD) by inhibiting the infiltration of inflammatory cells, and lowering serum levels of immunoglobulin $\mathrm{E}$ and histamine reducing the expression of cytokines (interleukin [IL]-4, IL-6, and tumor necrosis factor-alpha) and adhesion molecules (intercellular 
adhesion molecule-1 and vascular cell adhesion molecule-1). Geniposide, but not crocin, inhibited the release of histamine from mast cells, which may contribute to the anti-allergic effect of GJE and GJE-EA. ${ }^{87}$ Hydrolyzed gel of Gardenia jasminoides extract containing genipin was effective for the treatment of ecchymoses in a rat model. ${ }^{88}$

\section{Nephro-protective activity}

Potent uricosuric and nephro-protective effects activities of Gardenia jasminoides extract could also effectively reverse oxonate-induced alterations in renal urate transporter 1 (mURAT1), glucose transporter 9 (mGLUT9), organic anion transporter 1 (mOAT1), mOAT3, oncoprotein induced transcript 3 (mOIT3) expressions, as well as Tamm-Horsfall glycoprotein (THP) levels, resulting in the enhancement of renal uric acid excretion. Gardenia jasminoides extract significantly reduced serum urate levels and increased urinary urate levels and FEUA in hyperuricemic mice. It decreased serum creatinine, blood urea nitrogen (BUN), and fractional excretion of uric acid (FEUA) along with up-regulated expression of organic cation/carnitine transporters, improving renal dysfunction. ${ }^{89}$

\section{Retino-protective activity}

Protective effects of crocetin against retinal damage both of in vitro and in vivo by decreasing in caspase- 3 and caspase- 9 activities after retinal damage $^{90}$ and reducing oxidative stress in ischemia-induced retinal damage. ${ }^{91}$

\section{Anti-arthritis activity}

Geniposide healed arthritis through different mechanism like inhibiting the colonic inflammation damage in through decreasing the expression level of tumor necrosis factor-alpha (TNF- $\alpha$ ), interleukin-1(IL-1) and interleukin-6 (IL-6), increasing the production of interleukin-10 (IL-10) and restraining the expression of phospho-p38 (p-p38) related proteins in fibroblast-like synoviocyte proliferation..$^{92}$ Geniposide relieved significantly paw swelling and arthritis index and exerted immunoregulatory effects through inducing Th17 cell immune tolerance and enhancing Treg cell-mediated activities by down-regulating the expression of p-JNK signaling in mesenteric lymph node lymphocytes (MLNL) and peripheral blood lymphocytes (PBL) of adjuvant arthritis (AA) rats and decreased the expression of phospho-JNK (p-JNK) in MLNL and PBL of AA rats in the pathogenesis of rheumatoid arthritis ${ }^{92}$ and its potentiality in rheumatoid arthritis treatment proved in the previous study. ${ }^{93}$

\section{Anti-oxidant activity}

In terms of reducing power, free radical scavenging activities, aqueous extract of Gardenia jasminoides fruit exhibited higher anti-oxidant activity than that of its ethanolic extract ${ }^{94}$ and its anti-oxidant potential of methanolic extract of Gardenia jasminoides contributed due to phenolics and flavonoids in leaves. ${ }^{95}$ Geniposide possessed as a potential candidate for detoxification by inducing GST activity via increasing the transcription of GSTM1 and GSTM2 subunits ${ }^{96}$ leading to the activation of GSH S-transferase (GST) acting through MEK-1 pathway by activating and increasing expression of Ras/Raf/MEK-1 signaling mediators. ${ }^{97}$ Genipin quenched effectively 1, 1-diphenyl-2-picryl-hydrazyl (DPPH), a stable free radical, suggesting that genipin ${ }^{74}$ and crocetin $^{64}$ act as a direct free radical scavenger. GJE glycoprotein showed anti-oxidant effect against the lipid peroxidation process in the $\mathrm{Fe} 2^{+}$/ascorbic acid system blocking the formation of thiobarbituric acid-reactive substances. ${ }^{72}$ Increasing activities of anti-oxidative enzymes [catalase (CAT), superoxide dismutase (SOD), and glutathione peroxidase (GPx)], inhibition of inflammation related mediators (iNOS, COX-2, and NF-kappaB), production of nitric oxide (NO) and reactive oxygen species (ROS), myeloperoxidase (MPO) activity and thiobarbituric acid reactive substances (TBARS) levels, GJE glycoprotein $(80 \mathrm{microg} / \mathrm{ml})$ proved as a preventive and therapeutic agent for the ulcerative colitis. neutrophil infiltration and colonic lipid peroxidation due to its scavenging property. ${ }^{98}$ A novel anti-oxidant water-soluble polysaccharide was isolated from Gardenia jasminoides Ellis proved significant scavenging abilities. ${ }^{99}$

\section{Anti-apoptotic and anti-cancer activities}

Gardenia jasminoides extract exhibited anti-oxidative and anti-apoptotic effects in $\mathrm{HaCaT}$ cells by attenuating the UVB induced mRNA expressions of interleukin-1 $\beta$ (IL-1 $\beta$ ) and tumor necrosis factor- $\alpha$ (TNF- $\alpha$ ) in HaCaT cells. ${ }^{100}$ Dichloromethane fraction of Gardenia jasminoides extract was most efficient among n-hexane, ethyl acetate, n-butanol, and aqueous fractions in the mechanism of apoptosis led to the partial increase of caspase-3, caspase- 8 and caspase- 9 activities and the cleavage of poly (ADP-ribose) polymerase. ${ }^{101}$ Cytoprotective of geniposide exhibited through novel strategy by up regulating the expression of heme oxygenase-1 (HO-1) to attenuate the cell apoptosis induced by 3-morpholinosydnonimine hydrochloride (SIN-1); inducing the nuclear translocation of nuclear factor-E2-related factor 2 (Nrf2) and activation of phosphatidylinositol 3'-kinase (PI3K) and both LY294002 (a specific inhibitor of PI3K) and Zinc protoporphyrin (ZnPP, an inhibitor of $\mathrm{HO}$ 1) to antagonize oxidative stress in hippocampal neurons. ${ }^{102}$ Inhibitory effect of geniposide against formaldehyde-induced stress and apoptosis through increasing activity of intracellular anti-oxidants (superoxide dismutase and glutathione peroxidase); mRNA and protein levels of the anti-apoptotic gene Bcl-2 and geniposide protected SH-SY5Y cells by down regulating the expression of the apoptotic-related gene-P53, apoptotic executer-caspase 3 and apoptotic initiator-caspase 9. ${ }^{103}$ Geniposide alleviated mammary gland apoptosis by down regulating Bax expression along with TLR4 expression; inhibiting Caspase- 3 cleavage and preventing 553 phosphorylation and up-regulating $\mathrm{Bcl}-2$ expression in vivo. ${ }^{53}$ Anti-metastastic effect of Penta-acetyl geniposide [(Ac)(5)GP] exhibited an inhibitory effect on abilities of adhesion and motility by cell-matrix adhesion in the rat neuroblastoma line: C6 glioma cells by decreasing activity of matrix metalloproteinase-2 (MMP-2) and membrane type I matrix metalloproteinase (MT1-MMP) while enhancing the tissue inhibitor of matrix metalloproteinase-2 (TIMP-2), inhibiting phosphoinositide 3-kinase (PI3K) protein expression, phosphorylation of extracellular signalregulated kinases 1 and $2(\mathrm{ERK} 1 / 2)$ and activation of transcription factor nuclear factor kappa B (NF-kappaB), c-Fos, c-Jun. ${ }^{104}$ (Ac) 5GP decreased DNA damage and hepatocarcinogenesis induced by aflatoxin B1 (AFB1) by activating the phase II enzymes glutathione S-transferase (GST) and GSH peroxidase (GSH-Px); reducing the growth and development of inoculated C6 glioma cells; inducing sub-G1 peak through the activation of apoptotic cascades PKCdelta/JNK/Fas/caspase8 and caspase 3. (Ac) 5GP arrested cell cycle at G0/ G1 by inducing the expression of $\mathrm{p} 21$, thus suppressing the cyclin D1/cdk4 complex formation and the phosphorylation of E2F. ${ }^{105}$ Genipin exhibited a strong apoptotic cell death effect in human non-small-cell lung cancer H1299 cells mediated by an increase in phosphorylated p38MAPK expression, activated downstream signaling by phosphorylating ATF-2 and leading to increased levels of Bax counteractive to p38MAPK signaling. ${ }^{17}$ Genipin induced cell apoptosis in hepatoma cells and PC3 human prostate cancer cells due to increased significantly in the phosphorylated c-Jun $\mathrm{NH}(2)$-terminal kinase (JNK) protein, phospho-Jun protein, p53 protein and bax protein which led to the accumulation of bax protein, further induced cell apoptotic death eventually. ${ }^{106}$ Anti-proliferative activity of genipin in MDA-MB-231 exerted human breast cancer cells ${ }^{22}$ by similar mechanism in the previous studies. ${ }^{17,106}$ Genipin suppressed the constitutive STAT3 activation in U266 and U937 cells and stimulated Src homology 2 domain-containing phosphatase 1 (SHP-1), which dephosphorylates and inactivates STAT3 by blocking STAT3 activation via repressing the activation of c-Src, but 
not Janus kinase 1 (JAK1) and also down regulated the expression of STAT3 target genes including Bcl-2, Bcl-x(L), Survivin, Cyclin D1, and VEGF. Furthermore, genipin effectively potentiated the cytotoxic effect of chemotherapeutic agents, such as bortezomib, thalidomide, and paclitaxel in U266 cells. ${ }^{68}$ Genipin exhibited anti-tumor and anti-viral effects against Epstein-Barr virus (EBV) and EBV associated gastric carcinoma (EBVaGC) by significant cytotoxicity via inducing methylation on EBV C promoter and tumor suppressor gene BCL7A, arresting cellcycle progress (S phases), up regulating EBV latent/lytic genes, stimulating EBV progeny production, activating EBV F promoter for EBV lytic activation in SNU719 cells and suppressed EBV infection. ${ }^{107}$ Iridoid glycosides (IGs) exhibited anti-viral activity against influenza A virus via inhibition of intracellular acidification and $\mathrm{Ca}^{2+}$ influx during fusion and uncoating of influenza replication cycle. ${ }^{41}$ Protective and anti--apoptotic activities of GJE glycoprotein in $100 \mu \mathrm{g} / \mathrm{ml}$ exhibited significantly on the glucose/glucose oxidase (G/GO)-induced or hypoxanthine/xanthine oxidase (HX/XO)-induced cytotoxicity and apoptosis systems in NIH/3T3 cells, DNA fragmentation respectively by blocking activities against cytotoxicity and apoptosis; the activation of redox-sensitive signal mediators, protein kinase $\mathrm{C}$ alpha (PKCa) and nuclear factor-kappa B (NF- $\mathrm{kB}$ ) in G/GO or HX/XO-induced apoptotic NIH/3T3 cells. ${ }^{72}$

\section{Anti-angiogenic activity}

Butanol fraction of Gardenia jasminoides Ellis fruit was most effective agent among successive hexane, ethyl acetate and aqueous fractions for their nti-angiogenic activity in the bioassay. ${ }^{108}$ Geniposide showed antiangiogenic activity in a dose-dependent manner by inibiting the growth of the transformed NIH3T3 cell line within the range of 25-100 microM. ${ }^{2}$ Anti-angiogenic effects of crocetin suppressed on vascular endothelial growth factor (VEGF)-induced proliferation by inhibiting migration of human umbilical vein endothelial cells (HUVECs) and; human retinal microvascular endothelial cells (HRMECs) and phosphorylation of p38 significantly to protect VE-cadherin expression. ${ }^{109}$

\section{Anti-thrombotic activity}

Geniposide exhibited an anti-thrombotic effect via the suppression of platelet aggregation in vivo and inhibition of phospholipase-A(2) [(PLA (2)] activity acting as platelet antagonism. It inhibited activity resulting in significant decrease in EV71 virus infections, and internal ribosome entry site activity. Anti-enterovirus-71 (EV71) replication and viral IRES activity were inhibited by geniposide. ${ }^{110}$ Anti-thrombotic action of iridoid glycosides (IGs) were assessed that it may potentially contribute to the treatment of cerebral ischemic diseases, including cerebral apoplexy. ${ }^{111}$ Anti-hypertensive and anti-thrombotic effects of crocetin led to an increase in bioavailability of NO, possibly mediated by decreased inactivation of $\mathrm{NO}$ by reactive oxygen species. ${ }^{112}$

\section{Anti-microbial activity}

Bioassay-guided fractionation of 13 bioactive compounds from Gardenia jasminoides extracts exhibited anti-viral effects against influenza virus strain A/FM/1/47-MA in vivo. ${ }^{113}$ Dichloromethane extract of the air-dried flowers of Gardenia jasminoides Ellis afforded moderately active against Candida albicans; slightly active against E. coli, Pseudomonas aeruginosa, Staphylococcus aureus, and Trichophyton mentagrophytes; and inactive against Bacillus subtilis and Aspergillus niger. ${ }^{114}$ Methanolic extract of Gardenia jasminoides Ellis showed the highest level of antifungal activity against Pleurotus ostreatus, a wood-rotting fungus. ${ }^{115}$

\section{Miscellaneous activities}

Geniposide (GP) as an agonist of glucagon-like peptide-1 receptor (GLP-1R) through interaction of c-kit receptor with its ligand-SCF po- tent enhances norepinephrine (NE) induced hypopigmentation in the melanocytic melanogenesis. ${ }^{116,117}$ Genipin inhibited RANKL-induced osteoclast differentiation in bone marrow macrophages (BMMs) during culture by suppressing RANKL-induced I $\mathrm{B}$ degradation along with mRNA expression of osteoclastic markers such as NFATc1, TRAP, and OSCAR and inhibition of c-Fos protein proteolysis in RANKL-treated BMMs. Genipin could be qualified to be a candidate for the treatment of osteoporosis. ${ }^{118}$ Genipin was useful for treating periodontal disease by preventing MMPs expression like release of MMP-1, MMP-3 from TNF- $\alpha$-stimulated human periodontal cells. ${ }^{61}$ Crocetin revealed its hypnotic effect. ${ }^{119}$ Even a single administration of Gardenia jasminoides extract exhibited rapid anti-depressant effects in reducing the number of escape failures in the learned helplessness test significantly and decreased latency of food consumption in the novelty suppressed-feeding test with the elevated expression of brain-derived neurotrophic factor (BDNF) expression in the hippocampus. ${ }^{120}$ Oil extract of Gardenia jasminoides used for depression therapy. ${ }^{121}$

\section{Toxicity}

Acute hepatotoxicity of geniposide has been proved in the recent studies when it was administrated above normal dose of $24.3 \mathrm{mg} / \mathrm{kg}$ or higher doses leads to hepatic injury via oxidative stress. ${ }^{122,123}$ Genipin possesses genotoxicity. ${ }^{124}$ Genipin possessed a significant induction on CYP2D6 and a remarkable inhibition on CYP2C19 and CYP3A4 not only from the expression of mRNA and protein but the level of enzyme activity. Caution should be exercised with respect to the induction or inhibition of genipin on CYP isoenzymes and the strong induction on P-glycoprotein. ${ }^{125}$

\section{Patent review}

Patents are the largest single source of technical information in the world. Literature carries poor objective information regarding the technological strategies being adopted by the commercial companies in their research laboratories because of proprietary secrecy and less accessible of that technologies during their development phase. Patent analysis provides good evidence for the degree of patents filed by firms and inventors. It can also show the technological advances and recent developments in the particular area. ${ }^{126}$ Patents filed and granted on the use of Gardenia jasminoides alone or as active ingredient in the formulations were also considered for the review. Patent databases such as @espacenet and WIPO were searched and around 200 patents of interest retrieved in patent search and analysis which claimed for Gardenia jasminoides. However, analysis of these patents revealed that few of them mainly claim the method of extraction of active ingredient. Most of patents have been filed for TCM which were not included in the following table as these abstracts are difficult to interpret whether they are relevant to analyze.

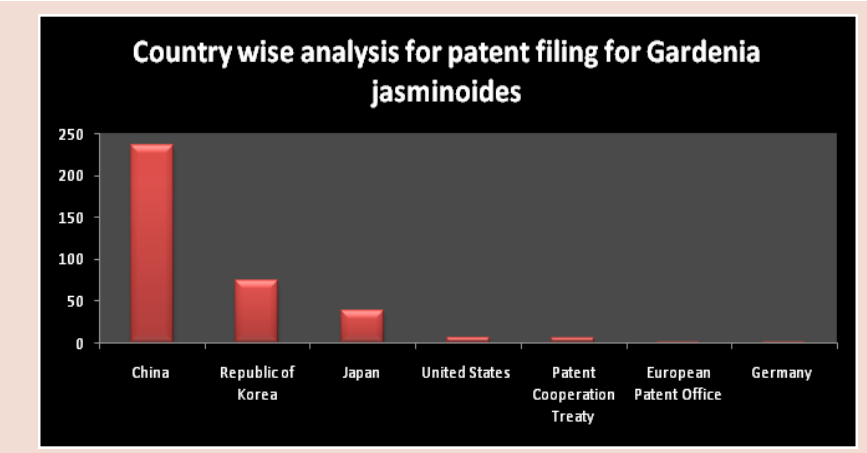

Figure 8: Country wise patent filling activity of Gardenia jasminoides 


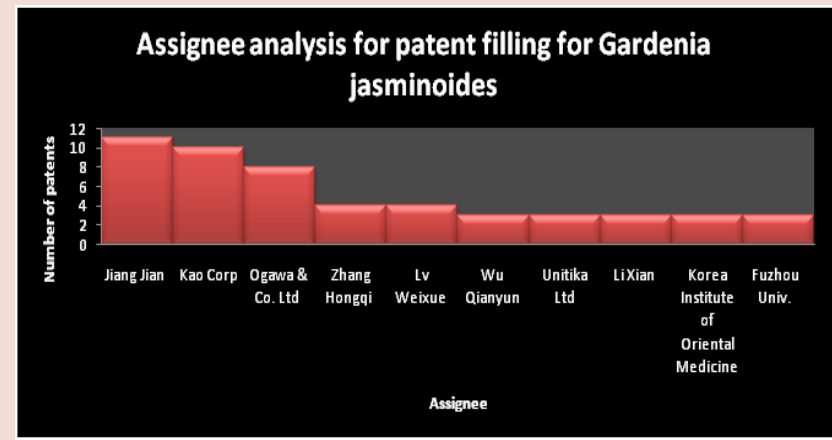

Figure 9: Assignee wise patent filling activity of Gardenia jasminoides Source: WIPO Patent analysis

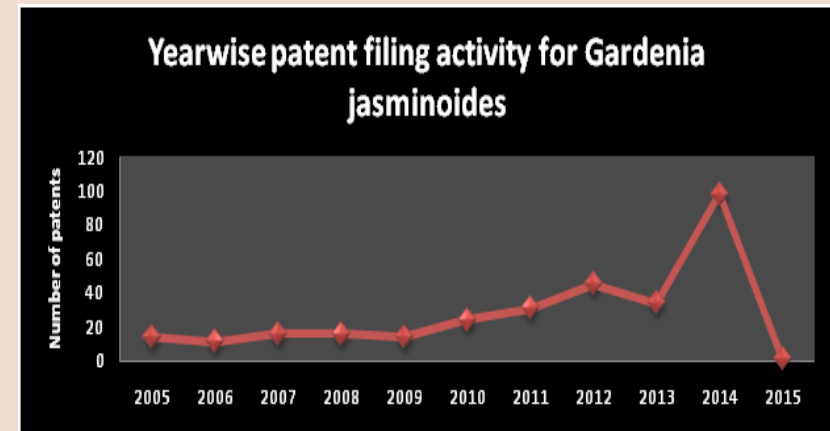

Figure 10: Year wise patent filling activity for Gardenia jasminoides

Table 2: Patent overview of Gardenia jasminoides

\begin{tabular}{|c|c|c|c|}
\hline Title & Publication number & $\begin{array}{l}\text { Publication date } \\
\text { date }\end{array}$ & Activity \\
\hline Method for treating abnormal polyglutamine-mediated diseases & US2015064287 & 2015-03-05 & Neuroprotective \\
\hline Extraction method of Gardenia jasminoides volatile oil & CN104164302 & 2014-11-26 & Extraction \\
\hline $\begin{array}{l}\text { A pharmaceutical composition comprising the hexane fraction of Gardenia jasminoides } \\
\text { extract as an effective component for anti-platelet aggregation and a health functional food } \\
\text { comprising the same }\end{array}$ & KR20140109099 & 2014-09-15 & $\begin{array}{l}\text { Anti-atherosclerotic } \\
\text { activity }\end{array}$ \\
\hline $\begin{array}{l}\text { Method used for preparing high-purity gardenoside and crocin from Gardenia jasminoides } \\
\text { Ellis }\end{array}$ & CN103951718 & 2014-07-30 & Extraction \\
\hline $\begin{array}{l}\text { Perfume composition for expressing the fragrance of Gardenia jasminoides Ellis for. } \\
\text { Grandiflora makino }\end{array}$ & KR20140030992 & 2014-03-12 & Cosmetic \\
\hline Rapid propagation method for Gardenia jasminoides & CN103461127 & 2013-12-25 & Cultivation \\
\hline Preparation method for Gardenia jasminoides gardenoside B & CN103435664 & 2013-12-11 & Extraction \\
\hline $\begin{array}{l}\text { Production water recovery device used in extraction process of Gardenia jasminoides } \\
\text { uranidin }\end{array}$ & CN203212364 & 2013-09-25 & Extraction \\
\hline $\begin{array}{l}\text { Method for preparation of gardenia oil, gardenia green pigment and gardenia blue pigment } \\
\text { through synchronous reaction }\end{array}$ & CN103060077 & 2013-04-24 & Extraction \\
\hline Gardenia jasminoides plant named Double Mint & USPP23507 & 2013-04-02 & Taxonomy \\
\hline Gardenia plant named 'BAB1183' & USPP22797 & 2012-03-08 & Taxonomy \\
\hline $\begin{array}{l}\text { Processing principle-based individualized and characteristic quality evaluation method for } \\
\text { Gardenia jasminoides Ellis decoction pieces }\end{array}$ & CN102335260 & 2012-02-01 & Taxonomy \\
\hline Gardenia jasminoides plant named 'leeone' & US2011162120 & 2011-06-30 & Taxonomy \\
\hline Interspecific hybidization of Gardenia jasminoides Ellis and G. thunbergia L. & USPP21541 & 2009-02-19 & Taxonomy \\
\hline $\begin{array}{l}\text { Glycoprotein isolated from Gardenia jasminoides Ellis, and hepatoprotective, } \\
\text { hypocholesterolemic and anti-inflammatory pharmaceutical composition containing the } \\
\text { glycoprotein }\end{array}$ & KR100661481 & 2006-12-19 & $\begin{array}{l}\text { Hepatoprotective, } \\
\text { hypocholesterolemic } \\
\text { anti-inflammatory }\end{array}$ \\
\hline Method for extracting genipin and geniposide from Gardenia jasminoides & CN101029066 & 2007-09-05 & Extraction \\
\hline Preparation of Gardenia jasminoides by membrane separation technology & CN1939459 & 2007-04-04 & Extraction \\
\hline Preparation of Gardenia jasminoides by macroporous adsorbing resin & CN1939458 & 2007-04-04 & Extraction \\
\hline Preparation of Gardenia jasminoides extracts & CN1939457 & 2007-04-04 & Extraction \\
\hline
\end{tabular}

\section{Country wise patent filing activity}

Patent filed on G. jasminoides as alone or formulations of TCM worldwide were revealed that patent applications have been increased over the last two decades. Among countries, China is the most one leading country to file patent on G. jasminoides as shown in Figure 8.

Assignee analysis

In the patent activity total number of patents applied by assignee is a simple indicator.

According to Figure 9, companies like Jiang Jian attained highest patent applications and Kao Corp from Japan hold second position among assignees worldwide.

\section{Year wise patent filing activity}

Priority year was considered for the analysis. The year wise analysis as depicted in Figure 10 revealed that the highest numbers of patent applications has been filed in the year 2014 and observed steady increase in the overall filings over the years (2005-2012) while patents filed in 2013 and 2014 are not considered as the data would be incomplete due to the reason that the patent applications are only published after a period of 18 
months from the date of filing.

\section{Technology analysis}

Pharmaceutical activity was considered as tool for technology strategies for the analysis. This technology analysis highlights that glycoprotein isolated from Gardenia jasminoides is effective for hepatoprotective, hypocholesterolemic anti-inflammatory activities while extract used as an anti-atherosclerotic and neuroprotective agent. Some of important patents related G. jasminoides have shown in Table 2.

\section{CONCLUSION}

Gardenia jasminoides has been used over many years in the Traditional Chinese Medicine (TCM). Till date it has been explored many pharmacologic activities and isolated many of active phytoconstituents using in the treatment of ailments and diseases. Apart from this, other countries has been increasingly curious attention in applying patents for specific isolated phytochemicals or Gardenia jasminoides in form of either aqueous or alcoholic extract exerting various pharmacologic activities like antiinflammatory, anti-cancer, anti-oxidant, hepatoprotective, gastro-protective, etc. Out of these assignees, China is the main leading country to be assignee for filing highest number of patents for Gardenia jasminoides in the field of traditional Chinese medicine. Yet there is no found updating review in research knowledge as Gardenia jasminoides is currently holding an enormous significant position in the medical and pharmaceutical fields. So there is a need of hour to structuralize the comprehensive review of scientific literature related to Gardenia jasminoides and to analyze patents filed for Gardenia jasminoides. As per the presented review herewith-Gardenia jasminoides is the medicinal herb being used since ancient times. Gardenia jasminoides extracts and its main active phytoconstituents viz; geniposide, genipin, crocin, crocetin have been reported with extended pharmacological activities such as anti-hyperglycemic, anti-atherosclerotic, anti-inflammatory, anti-arthritis, anti-cancer, anti-apoptotic, anti-oxidant, anti-angiogenic, anti-thrombotic, anti-microbial and miscellaneous activities. Also it has been explored through different protective mechanisms like neuroprotective for Alzheimer's disease (AD), hepatoprotective, gastro-protective, retino-protective, nephroprotective, skin protective activities. Even though it is well documented of numerous health benefits of GJ, acute hepatotoxicity of geniposide has been reported in the recent studies when it was administrated in higher doses of geniposide. Pharmacokinetic and pharmacodynamic studies of geniposide should be investigated to prevent inducing hepatic injury due to overdoses. This data provides scientific scenario will helpful for developing research strategies and art of patent will also help in identifying the research drawbacks for generating intellectual property.

\section{ACKNOWLEDGMENT}

Author expresses his gratitude to Dipti Potdar-Jadhav for her assistance.

\section{CONFLICTS OF INTEREST}

Author declares that there is no conflict of interest.

\section{REFERENCES}

1. Koo HJ, Lim KH, Jung HJ, Park EH. Anti-inflammatory evaluation of Gardenia extract geniposide and genipin. J Ethnopharmacol. 2006; 103(3): 496-500.

2. Koo HJ, Lee S, Shin KH, Kim BC, Lim CJ, Park EH. Geniposide, an anti-angiogenic compound from the fruits of Gardenia jasminoides. Planta Med. 2004; 70(5): 467-9.

3. Parmar VS, Sharma SK, Poonam. Novel Constituents of Gardenia species-A Review. J Sci Ind Res. 2000; 59(11): 893-903.

4. Wu X, Zhou Y, Yin F, Mao C, Li L, Cai B, et al. Quality control and producing areas differentiation of Gardeniae fructus for eight bioactive constituents by HPLCDAD-ESI/MS. Phytomedicine 2014; 21(4): 551-9.

5. Luo YJ, Zuo YM, Zhang ZL, Cai MT, Luo GM. Study on chemical constituents of
Gardenia jasminoides (III). Zhong Yao Cai Journal of Chinese medicinal materials 2014; 37(7): 1196-9.

6. Qin FM, Liu BL, Zhang Y, Zhou GX. A new triterpenoid from the fruits of Gardenia jasminoides var. radicans Makino. Nat Prod Res. 2015; 29(7): 633-7.

7. Jia-Ling Song, Rui Wang, Yan-Ping Shi, Huan-Yang Qi. Iridoids from the flowers of Gardenia jasminoides Ellis and their chemotaxonomic significance. Biochemical Systematics and Ecology 2014; 56: 267-70.

8. Qin FM, Meng LJ, Zou HL, Zhou GX. Three new iridoid glycosides from the fruit of Gardenia jasminoides var. radicans. Chem Pharm Bull. 2013; 61(10): 1071-4.

9. Hai-Bo Li, Yang Yu, Zhen-Zhong Wang, Yi Dai, Hao Gao, Wei Xiao, et al. Iridoid and bis-iridoid glucosides from the fruit of Gardenia jasminoides. Fitoterapia 2013; 88(1): 7-11.

10. Kwak SC, Lee C, Kim JY, Oh HM, So HS, Lee MS, et al. Chlorogenic acid inhibits osteoclast differentiation and bone resorption by down-regulation of recepto activator of nuclear factor kappa-B ligand-induced nuclear factor of activated $\mathrm{T}$ cells c1 expression. Biol Pharm Bull. 2013; 36(11): 1779-86.

11. Liguo Yang, Kaifeng Peng, Shizhe Zhao, Feng Zhao, Lixia Chen, Feng Oiu 2-Methyl---erythritol glycosides from Gardenia jasminoides. Fitoterapia 2013; 89(2): 126-30.

12. Zuo YM, Zhang ZL, Yang YQ, Luo GM, Cai CJ, Wang YY. Study on the chemical components of Gardenia jasminoides. Zhong Yao Cai 2013; 36(2): 225-7.

13. Liguo Yang, Kaifeng Peng, Shizhe Zhao, Lixia Chen, Feng Qiu. Monoterpenoids from the fruit of Gardenia jasminoides Ellis (Rubiaceae). Biochemical Systematics and Ecology 2013; 50(1): 435-7.

14. Song JL, Yang YJ, Qi HY, Li Q. Chemical constituents from flowers of Gardenia jasminoides. Zhong Yao Cai. 2013; 36(5): 752-5.

15. Rao AS, Chary JS, Merugu R. Iridoids from Gardenia jasminoides Ellis. Int J Chem Tech Res. 2013; 5(1): 418-21.

16. Li HB, Yu Y, Wang ZZ, Dai Y, Gao H, Xiao W, et al. Iridoid and bis-iridoid glucosides from the fruit of Gardenia jasminoides. Fitoterapia 2013; 88: 7-11.

17. Yang L, Peng K, Zhao S, Zhao F, Chen L, Qiu F. 2-methyl-L-erythritol glycosides from Gardenia jasminoides. Fitoterapia 2013; 89: 126-30.

18. Zhang ZL, Zuo YM, Luo GM, Luo YJ, Wang YY, Yang YQ. Study on the chemical components of Gardenia jasminoides (II). Biol Pharm Bull. 2013; 36(11): 177986.

19. Peng K, Yang L, Zhao S, Chen L, Zhao F, Qiu F. Chemical constituents from the fruit of Gardenia jasminoides and their inhibitory effects on nitric oxide production. Bio org Med Chem Lett. 2013; 23(4): 1127-31.

20. Wang J, Lu J, Lv C, Xu T, Jia L. Three new triterpenoid saponins from root of Gardenia jasminoides Ellis. Fitoterapia 2012; 83(8): 1396-401.

21. YuY, Feng $X L, G a o H$, Xie ZL, Dai Y, Huang XJ, et al. Chemical constituents from the fruits of Gardenia jasminoides Ellis. Fitoterapia 2012; 83(3): 563-7.

22. Kim JH, Kim GH, Hwang KH. Monoamine Oxidase and Dopamine $\beta$-Hydroxylase Inhibitors from the Fruits of Gardenia jasminoides. Biomol Ther. 2012; 20(2): 214-9.

23. Huang T, Mu SZ, Hao XJ. Study on the chemical constituents of Fructus gardeniae. Zhong Yao Cai Journal of Chinese medicinal materials 2012; 35(12): 1950-2.

24. Akihisa T, Watanabe K, Yamamoto A, Zhang J, Matsumoto M, Fukatsu M. Melanogenesis inhibitory activity of monoterpene glycosides from Gardeniae fructus. Chem Biodivers. 2012; 9(8): 1490-9.

25. Yu Y, Gao H, Dai Y, Xiao GK, Zhu HJ, Yao XS. Guaiane-type sesquiterpenoid glucosides from Gardenia jasminoides Ellis. Magn Reson Chem. 2011; 49(5): 258-61.

26. Clifford MN, Wu W, Kirkpatrick J, Jaiswal R, Kuhnert N. Profiling and characterisation by liquid chromatography/multi-stage mass spectrometry of the chlorogenic acids in Gardeniae fructus. Rapid Commun Mass Spectrom 2010; 24(21): 3109-20.

27. Jarubol Chaichana, Wirat Niwatananun, Suwanna Vejabhikul, Sudsawad Somna, Sunee Chansakaow. Volatile constituents and biological activities of Gardenia jasminoides. J Health Res. 2009; 23(3): 141-5.

28. Chen QC, Zhang WY, Youn U, Kim H, Lee I, Jung HJ, et al. Iridoid glycosides from Gardeniae fructus for treatment of ankle sprain. Phytochemistry 2009; 70(6): 779-84

29. Yu Y, Xie ZL, Gao H, Ma WW, Dai Y, Wang Y, Zhong Y, Yao XS. Bioactive iridoid glucosides from the fruit of Gardenia jasminoides. J Nat Prod. 2009; 72(8) 1459-64.

30. Li BL, Chen YH, Hu R, Tang JJ, Zhao LM, Yuan BX. Sedative, hypnotic and antiseizure effects of compound gardenia oil and jujube seed oil in mice. Nan Fang Yi Ke Da Xue Xue Bao 2008; 28(9): 1636-9.

31. Chen QC, Youn U, Min BS, Bae K. Pyronane monoterpenoids from the fruit of Gardenia jasminoides. J Nat Prod. 2008; 71(6): 995-9.

32. Chen $H$, Xiao YQ, Li L, Zhang C. Studies on chemical constituents in fruit of Gardenia jasminoides. Zhongguo Zhong Yao Za Zhi 2007; 32(11): 1041-3.

33. Kim HJ, Kim EJ, Seo SH, Shin CG, Jin C, Lee YS. Vanillic acid glycoside and quinic acid derivatives from Gardeniae fructus. J Nat Prod. 2006; 69(4): 600-3.

34. Chang WL, Wang HY, Shi LS, Lai JH, Lin HC. Immunosuppressive iridoids from the fruits of Gardenia jasminoides. J Nat Prod. 2005; 68(11): 1683-5. 
35. Machida K, Takehara E, Kobayashi H, Kikuchi M. Studies on the constituents of Gardenia species. III. New iridoid glycosides from the leaves of Gardenia jasminoides cv. Chem Pharm Bull. 2003; 51(12): 1417-9.

36. Machida K, Oyama K, Ishii M, Kakuda R, Yaoita Y, Kikuchi M. Studies of the constituents of Gardenia species. II. Terpenoids from Gardeniae fructus. Chem Pharm Bull. 2000; 48(5): 746-8.

37. Chen YI, Cheng YW, Tzeng CY, Lee YC, Chang YN, Lee SC, et al. Peroxisome proliferator-activated receptor activating hypoglycemic effect of Gardenia jasminoides Ellis aqueous extract and improvement of insulin sensitivity in steroid induced insulin resistant rats. BMC Complement Altern Med. 2014; 14(1): 30.

38. Jung WS, Chae YS, Kim DY, Seo SW, Park HJ, Bae GS, et al. Gardenia jasminoides protects against cerulein-induced acute pancreatitis. World J Gastroenterol. 2008; 14(40): 6188-94

39. Wu SY, Wang GF, Liu ZQ, Rao JJ, Lü L, Xu W, et al. Effect of geniposide, a hypoglycemic glucoside, on hepatic regulating enzymes in diabetic mice induced by a high-fat diet and streptozotocin. Acta Pharmacol Sin. 2009; 30(2): 202-8.

40. Zhang Y, Yin F, Liu J, Wang Y. Geniposide protects pancreatic INS-1E $\beta$ cells from hIAPP-induced cell damage: Potential involvement of insulin degradingenzyme. Cell Biol Int. 2015; 39(4): 373-8.

41. Guo LX, Liu JH, Yin F. Regulation of insulin secretion by geniposide: possible involvement of phosphatidylinositol 3-phosphate kinase. Eur Rev Med Pharmaco Sci. 2014; 18(9): 1287-94.

42. Wang GF, Wu SY, Xu W, Jin H, Zhu ZG, Li ZH, et al. Geniposide inhibits high glucose-induced cell adhesion through the NF-kappaB signaling pathway in human umbilical vein endothelial cells. Acta Pharmacol Sin. 2010; 31 (8): 953-62.

43. Hwang SM, Lee YJ, Yoon JJ, Lee SM, Kang DG, Lee HS. Gardenia jasminoides inhibits tumor necrosis factor-alpha-induced vascular inflammation in endothelial cells. Phytother Res. 2010; 24 (Suppl 2): S214-9.

44. Liao P, Liu L, Wang B, Li W, Fang X, Guan S. Baicalin and geniposide attenuate atherosclerosis involving lipids regulation and immuno regulation in ApoE-/mice. Eur J Pharmacol. 2014; 740(1): 488-95.

45. Kojima K, Shimada T, Nagareda Y, Watanabe M, Ishizaki J, Sai Y, et al. Preventive effect of geniposide on metabolic disease status in spontaneously obese type 2 diabetic mice and free fatty acid-treated HepG2 cells. Biol Pharm Bull. 2011; 34(10): 1613-8.

46. Gao Y, Chen ZY, Liang X, Xie C, Chen YF. Anti-atherosclerotic effect of geniposidic acid in a rabbit model and related cellular mechanisms. Pharm Biol. 2015; 53(2): 280-5

47. Guan L, Feng H, Gong D, Zhao X, Cai L, Wu Q, et al. Genipin ameliorates agerelated insulin resistance through inhibiting hepatic oxidative stress and mitochondrial dysfunction. Exp Gerontol. 2013; 48(12): 1387-94

48. Ma CJ, Nie AF, Zhang ZJ, Zhang ZG, Du L, Li XY, et al. Genipin stimulates glucose transport in C2C12 myotubes via an IRS-1 and calcium-dependent mechanism. J Endocrinol. 2013; 216(3): 353-62

49. Xi L, Qian Z, Shen X, Wen N, Zhang Y. Crocetin prevents dexamethasone-induced insulin resistance in rats. Planta Med. 2005; 71(10): 917-22.

50. Sheng L, Qian Z, Zheng S, Xi L. Mechanism of hypolipidemic effect of crocin in rats: crocin inhibits pancreatic lipase. Eur J Pharmacol. 2006; 543(1-3): 116-22.

51. Lee IA, Lee JH, Baek NI, Kim DH. Antihyperlipidemic effect of crocin isolated from the fructus of Gardenia jasminoides and its metabolite Crocetin. Biol Pharm Bull. 2005; 28(11): 2106-10.

52. Zheng $X$, Yang D, Liu X, Wang N, Li B, Cao H, et al. Identification of a new antiLPS agent, geniposide, from Gardenia jasminoides Ellis, and its ability of direct binding and neutralization of lipopolysaccharide in vitro and in vivo. Int Immunopharmacol. 2010; 10(10): 1209-19.

53. Song $X$, Zhang W, Wang T, Jiang H, Zhang Z, FuY, et al. Geniposide plays an antiinflammatory role via regulating TLR4 and downstream signaling pathways in lipopolysaccharide-induced mastitis in mice. Inflammation 2014; 37(5): 1588-98.

54. Fu Y, Liu B, Liu J, Liu Z, Liang D, Li F, et al. Geniposide, from Gardenia jasminoides Ellis, inhibits the inflammatory response in the primary mouse macrophages and mouse models. Int Immunopharmacol. 2012; 14(4): 792-8.

55. Zhang G, He JL, Xie XY, Yu C. LPS-induced iNOS expression in N9 microglial cells is suppressed by geniposide via ERK, p38 and nuclear factor- $\mathrm{KB}$ signaling pathways. Int J Mol Med. 2012; 30(3): 561-8

56. Deng Y, Guan M, Xie X, Yang X, Xiang H, Li H, et al. Geniposide inhibits airway inflammation and hyper responsiveness in a mouse model of asthma. Int Immunopharmacol. 2013; 17(3): 561-7.

57. Xiaofeng Y, Qinren C, Jingping H, Xiao C, Miaomiao W, Xiangru F, et al. Geniposide, an iridoid glucoside derived from Gardenia jasminoides, protects against lipopolysaccharide-induced acute lung injury in mice. Planta Med. 2012; 78(6): 557-64.

58. Shi Q, Cao J, Fang L, Zhao H, Liu Z, Ran J, et al. Geniposide suppresses LPS-induced nitric oxide, PGE2 and inflammatory cytokine by down regulating NF-кB, MAPK and AP-1 signaling pathways in macrophages. Int Immunopharmacol. 2014; 20(2): 298-306.

59. Chen QC, Zhang WY, Kim H, Lee IS, Ding Y, Youn UJ, et al. Effects of Gardeniae fructus extract and geniposide on promoting ligament cell proliferation and collagen synthesis. Phytother Res. 2010; (24 Suppl 1): S1-5.

60. Chia-Cheng Li, Chien-Yun Hsiang, Hsin-Yi Lo, Fu-Tzu Pai, Shih-Lu Wu, Tin-Yun
Ho. Genipin inhibits lipopolysaccharide-induced acute systemic inflammation in mice as evidenced by nuclear factor- $\mathrm{B} B$ bioluminescent imaging-guided transcriptomic analysis. Food and Chemical Toxicology 2012; 50(9): 2978-86.

61. Shindo S, Hosokawa Y, Hosokawa I, Ozaki K, Matsuo T. Genipin inhibits IL-1 $\beta$ induced CCL20 and IL-6 production from human periodontal ligament cells. Cell Physiol Biochem. 2014; 33(2): 357-64.

62. Khanal T, Kim HG, Do MT, Choi JH, Chung YC, Kim HS, et al. Genipin induces cyclooxygenase-2 expression via NADPH oxidase, MAPKs, AP-1, and NF-kB in RAW 264.7 cells. Food Chem Toxicol. 2014; 64(1): 126-34.

63. Araki R, Hiraki Y, Yabe T. Genipin attenuates lipopolysaccharide-induced persistent changes of emotional behaviors and neural activation in the hypothalamic para ventricular nucleus and the central amygdala nucleus. Eur J Pharmacol. 2014; 741(1): 1-7.

64. Hong YJ, Yang KS. Anti-inflammatory activities of crocetin derivatives from processed Gardenia jasminoides. Arch Pharm Res. 2013; 36(8): 933-40.

65. Kim JH, Park GY, Bang SY, Park SY, Bae SK, Kim Y. Crocin suppresses LPSstimulated expression of inducible nitric oxide synthase by up regulation of heme oxygenase-1 via calcium/calmodulin-dependent protein kinase 4. Mediators Inflamm. 2014; 2014(1): 728709.

66. Xu GL, Li G, Ma HP, Zhong H, Liu F, Ao GZ. Preventive effect of crocin in inflamed animals and in LPS-challenged RAW 264.7 cells. J Agric Food Chem. 2009; 57(18): 8325-30.

67. Yang R, Yang L, Shen X, Cheng W, Zhao B, Ali KH, et al. Suppression of NF-кB pathway by crocetin contributes to attenuation of lipo polysaccharide-induced acute lung injury in mice. Eur J Pharmacol. 2012; 674(2-3): 391-6.

68. Lee J, Lim KT. Preventive effect of phyto glycoprotein $(27 \mathrm{kDa})$ on inflammatory factors at liver injury in cadmium chloride-exposed ICR mice. J Cell Biochem. 2011; 112(2): 694-703

69. Choi SJ, Kim MJ, Heo HJ, Hong B, Cho HY, Kim YJ, et al. Ameliorating effect of Gardenia jasminoides extract on amyloid beta peptide-induced neuronal cell deficit. Mol Cells. 2007; 24(1): 113-8.

70. Lv C, Liu X, Liu H, Chen T, Zhang W. Geniposide attenuates mitochondrial dysfunction and memory deficits in APP/PS1 transgenic mice. Curr Alzheimer Res. 2014; 11(6): 580-7.

71. Nam Y, Lee D. Ameliorating effect of zhizi (Fructus gardeniae) extract and its glycosides on scopolamine-induced memory impairment. J Tradit Chin Med. 2013; 33(2): 223-7.

72. Lee P, Lee J, Choi SY, Lee SE, Lee S, Son D. Geniposide from Gardenia jasminoides attenuates neuronal cell death in oxygen and glucose deprivation-exposed rat hippocampal slice culture. Biol Pharm Bull. 2006; 29(1): 174-6.

73. Lv C, Wang L, Liu X, Cong X, Yan SS, Wang Y, et al. Geniposide attenuates oligomeric $A \beta(1-42)$-induced inflammatory response by targeting RAGE-dependent signaling in BV2 cells. Curr Alzheimer Res. 2014; 11(5): 430-40.

74. Lv C, Wang L, Liu X, Yan S, Yan SS, Wang Y, et al. Multi-faced neuroprotective effects of geniposide depending on the RAGE-mediated signaling in an Alzheimer mouse model. Neuropharmacology 2015; 89(1): 175-84.

75. Hughes RH, Silva VA, Ahmed I, Shreiber DI, Morrison B. Neuroprotection by genipin against reactive oxygen and reactive nitrogen species-mediated injury in organotypic hippocampal slice cultures. Brain Res. 2014; 1543(1): 308-14.

76. Nam KN1, Choi YS, Jung HJ, Park GH, Park JM, Moon SK, et al. Genipin inhibits the inflammatory response of rat brain microglial cells. Int Immunopharmacol. 2010; 10(4): 493-9.

77. Yamazaki M, Chiba K, Yoshikawa C. Genipin suppresses A23187-induced cytotoxicity in neuro2a cells. Biol Pharm Bull. 2009; 32(6): 1043-6.

78. Nam KN, Park YM, Jung HJ, Lee JY, Min BD, Park SU, et al. Anti-inflammatory effects of crocin and crocetin in rat brain microglial cells. Eur J Pharmacol. 2010 648(1-3): $110-6$

79. Chen YH, Lan T, Li J, Qiu CH, Wu T, Gou HJ, et al. Gardenia jasminoides attenuates hepatocellular injury and fibrosis in bile duct-ligated rats and human hepatic stellate cells. World J Gastroenterol. 2012; 18(48): 7158-65.

80. Wang J, Zhang Y, Liu R, Li X, Cui Y, Qu L. Geniposide protects against acute alcohol-induced liver injury in mice via up-regulating the expression of the main antioxidant enzymes. Can J Physiol Pharmacol. 2015; 93(4): 1-7.

81. Kim SJ, Kim KM, Park J, Kwak JH, Kim YS, Lee SM. Geniposidic acid protects against D-galactosamine and lipopolysaccharide-induced hepatic failure in mice. J Ethnopharmacol. 2013; 146(1): 271-7.

82. Wei J1, Zhang F, Zhang Y, Cao C, Li X, Li D, et al. Proteomic investigation of signatures for geniposide-induced hepatotoxicity. J Proteome Res. 2014; 13(12): 5724-33.

83. Kim SJ, Kim JK, Lee DU, Kwak JH, Lee SM. Genipin protects lipopolysaccharide-induced apoptotic liver damage in D-galactosamine-sensitized mice. Eur J Pharmacol. 2010; 635(1-3): 188-93.

84. Tang FT1, Qian ZY, Liu PQ, Zheng SG, He SY, Bao LP, et al. Crocetin improves endothelium-dependent relaxation of thoracic aorta in hypercholesterolemic rabbit by increasing eNOS activity. Biochem Pharmacol. 2006; 72(5): 558-65.

85. Lee JH, Kang KJ, Lee YM, Kim PN, Jeong CS. Effects of Gardenia jasminoides Ellis ethanol extract and its constituents on anti-gastritis and anti-gastric cance cells. Planta Med. 2008; 74(09): 289

86. Lee JH, Lee DU, Jeong CS. Gardenia jasminoides Ellis ethanol extract and its 
constituents reduce the risks of gastritis and reverse gastric lesions in rats Food Chem Toxicol. 2009; 47(6): 1127-31.

87. Sung YY, Lee AY, Kim HK. The Gardenia jasminoides extract and its constituent, geniposide, elicit anti-allergic effects on atopic dermatitis by inhibiting histamine in vitro and in vivo. J Ethnopharmacol. 2014; 156: 33-40.

88. Hwang K, Choi HG, Kim DJ, Hwang SH. The effect of hydrolyzed Gardeniae fructus extract hydrogel on the treatment of ecchymoses in a rat model. Dermatol Surg. 2009; 35(10): 1525-31.

89. Hu QH, Zhu JX, Ji J, Wei LL, Miao MX, Ji H. Fructus gardenia Extract ameliorates oxonate-induced hyperuricemia with renal dysfunction in mice by regulating organic ion transporters and mOIT3. Molecules 2013; 18(8): 8976-93.

90. Yamauchi M, Tsuruma K, Imai S, Nakanishi T, Umigai N, Shimazawa M, et al. Crocetin prevents retinal degeneration induced by oxidative and endoplasmic reticulum stresses via inhibition of caspase activity. Eur J Pharmacol. 2011; 650(1): 110-9.

91. Ishizuka F, Shimazawa M, Umigai N, Ogishima H, Nakamura S, Tsuruma K, et al. Crocetin, a carotenoid derivative, inhibits retinal ischemic damage in mice. Eur J Pharmacol. 2013; 703(1-3): 1-10.

92. Chen JY, Wu H, Li H, Hu SL, Dai MM, Chen J. Anti-inflammatory effects and pharmacokinetics study of geniposide on rats with adjuvant arthritis. Int Immunopharmacol. 2015; 24(1): 102-9.

93. Chen J, Wu H, Dai MM, Li H, Chen JY, Hu SL. Identification and distribution of four metabolites of geniposide in rats with adjuvant arthritis. Fitoterapia 2014 97: 111-21.

94. Debnath T, Park PJ, Nath NCD, Samad NB, Park HW, Lima BO. Antioxidant activity of Gardenia jasminoides Ellis fruit extracts. Food Chem. 2011; 128(3): 697-703.

95. Uddin R, Saha MR, Subhan N, Hossain H, Jahan IA, Akter R, et al. HPLC-analysis of polyphenolic compounds in Gardenia jasminoides and determination of antioxidant activity by using free radical scavenging assays. Adv Pharm Bull. 2014; 4(3): 273-81.

96. Kuo WH, Wang CJ, Young SC, Sun YC, Chen YJ, Chou FP. Differential induction of the expression of GST subunits by geniposide in rat hepatocytes. Pharmacology 2004; 70(1): 15-22.

97. Kuo WH, Chou FP, Young SC, Chang YC, Wang CJ. Geniposide activates GSH S-transferase by the induction of GST M1 and GST M2 subunits involving the transcription and phosphorylation of MEK-1 signaling in rat hepatocytes. Toxicol Appl Pharmacol. 2005; 208(2): 155-62.

98. Oh PS, Lim KT. Plant originated glycoprotein has anti-oxidative and anti-inflammatory effects on dextran sulfate sodium-induced colitis in mouse. J Biomed Sci. 2006; 13(4): 549-60.

99. Ellis Yijun Fan, Zhongfu Ge and Aoxue Luo. In vitro antioxidant activity of polysaccharide from Gardenia jasminoides. Journal of Medicinal Plants Research 2011; 5(14): 2963-8.

100. Park J, Seok JK, Suh HJ, Boo YC. Gardenia jasminoides extract attenuates the UVB-induced expressions of cytokines in keratinocytes and indirectly inhibits matrix metalloproteinase-1 expression in human dermal fibroblasts. Evid Based Complement Alternat Med. 2014; 2014(1): 429246.

101. Lim W, Kim O, Jung J, Ko Y, Ha J, Oh H, et al. Dichloromethane fraction from Gardenia jasminoides DNA topoisomerase 1 inhibition and oral cancer cell death induction. Pharm Biol. 2010; 48(12): 1354-60

102. Yin F, Liu J, Zheng X, Guo L, Xiao H. Geniposide induces the expression of heme oxygenase-1 via PI3K/Nrf2-signaling to enhance the antioxidant capacity in primary hippocampal neurons. Biol Pharm Bull. 2010; 33(11): 1841-6.

103. Sun $P, C$ hen JY, Li J, Sun MR, Mo WC, Liu KL, et al. The protective effect of geniposide on human neuroblastoma cells in the presence of formaldehyde. BMC Complement Altern Med. 2013; 13(1): 152.

104. Huang HP, Shih YW, Wu CH, Lai PJ, Hung CN, Wang CJ. Inhibitory effect of penta-acetyl geniposide on $\mathrm{C} 6$ glioma cells metastasis by inhibiting matrix metalloproteinase-2 expression involved in both the PI3K and ERK signaling pathways. Chem Biol Interact. 2009; 181(1): 8-14

105. Peng $\mathrm{CH}$, Huang $\mathrm{CN}$, Wang CJ. The anti-tumor effect and mechanisms of action of penta-acetyl geniposide. Curr Cancer Drug Targets 2005; 5(4): 299-305.
106. Cao H, Feng Q, Xu W, Li X, Kang Z, Ren Y, et al. Genipin induced apoptosis associated with activation of the c-Jun $\mathrm{NH} 2$-terminal kinase and p53 protein in HeLa cells. Biol Pharm Bull. 2010; 33(8): 1343-8.

107. Son M, Lee M, Ryu E, Moon A, Jeong CS, Jung YW, et al. Genipin as a novel chemical activator of EBV lytic cycle. J Microbiol. 2015; 53(2): 155-65.

108. Park EH, Joo MH, Kim SH, Lim CJ. Antiangiogenic activity of Gardenia jasminoides fruit. Phytother Res. 2003; 17(8): 961-2.

109. Umigai N, Tanaka J, Tsuruma K, Shimazawa M, Hara H. Crocetin, a carotenoid derivative, inhibits VEGF-induced angiogenesis via suppression of p38 phosphorylation. Curr Neurovasc Res. 2012; 9(2): 102-9.

110. Lin YJ, Lai CC, Lai CH, Sue SC, Lin CW, Hung CH, et al. Inhibition of enterovirus 71 infections and viral IRES activity by Fructus gardeniae and geniposide. Eur J Med Chem. 2013; 62(1): 206-13.

111. Wang P, Wang Q, Luo C, Tan C, Yuan X. Iridoid glycosides extracted from zhizi (Fructus gardeniae) decrease collagen-induced platelet aggregation and reduce carotid artery thrombosis in an in vivo rat model. J Tradit Chin Med. 2013; 33(4): 531-4.

112. Higashino S, Sasaki Y, Giddings JC, Hyodo K, Sakata SF, Matsuda K, et al. Crocetin, a carotenoid from Gardenia jasminoides Ellis, protects against hypertension and cerebral thrombogenesis in stroke-prone spontaneously hypertensive rats. Phytother Res. 2014; 28(9): 1315-9

113. Yang R, Yang L, Shen X, Cheng W, Zhao B, Ali KH, et al. Suppression of NF- $\kappa B$ pathway by crocetin contributes to attenuation of lipopolysaccharide-induced acute lung injury in mice. European Journal of Pharmacology 2012; 674 (2-3): 391-6.

114. Ragasa CY, Pimenta LE, Rideout JA. Iridoids from Gardenia jasminoides. Nat Prod Res 2007; 21(12):1078-84.

115. Lelono RA, Tachibana S, Itoh K. Isolation of antifungal compounds from Gardenia jasminoides. Pak J Biol Sci. 2009; 12(13): 949-56.

116. Lan WJ, Wang HY, Lan W, Wang KY. Geniposide enhances melanogenesis by stem cell factor/c-Kit signalling in norepinephrine-exposed normal human epidermal melanocyte. Basic Clin Pharmacol Toxicol. 2008; 103(1): 88-93.

117. Wen-Jun L, Hai-Yan W, Wei L, Ke-Yu W, Rui-Ming W. Evidence that geniposide abrogates norepinephrine-induced hypo pigmentation by the activation of GLP-1R-dependent c-kit receptor signaling in melanocyte. J Ethnopharmacol. 2008; 118(1): 154-8.

118. Lee $\mathrm{CH}$, Kwak SC, Kim JY, Oh HM, Rho MC, Yoon $\mathrm{KH}$, et al. Genipin inhibits RANKL-induced osteoclast differentiation through proteasome-mediated degradation of c-Fos protein and suppression of NF-kB activation. J Pharmacol Sci. 2014; 124(3): 344-53

119. Kuratsune H, Umigai N, Takeno R, Kajimoto Y, Nakano T. Effect of crocetin from Gardenia jasminoides Ellis on sleep: a pilot study. Phytomedicine 2010; 17(11): 840-3.

120. Zhang $H$, Xue W, Wu R, Gong $T$, Tao W Zhou X et al. Rapid antidepressant activity of ethanol extract of Gardenia Jasminoides Ellis is associated with up regulation of BDNF expression in the hippocampus. Evid Based Complement Alternat Med. 2015; 2015(1): 761238.

121. TaoW, Zhang H, Xue W, Ren L, Xia B, Zhou X, et al. Optimization of supercritical fluid extraction of oil from the fruit of Gardenia jasminoides and its antidepressant activity. Molecules 2014; 19(12): 19350-60.

122. Yang HJ, Fu MH, Wu ZL, Liang RX, Huang LQ, Fang J, et al. Experimental studies on hepatotoxicity of rats induced by Fructus gardeniae. Zhongguo Zhong Yao Za Zhi 2006; 31(13): 1091-3.

123. Ding Y, Zhang T, Tao JS, Zhang LY, Shi JR, Ji G. Potential hepatotoxicity of geniposide, the major iridoid glycoside in dried ripe fruits of Gardenia jasminoides (Zhi-zi). Nat Prod Res. 2013; 27(10): 929-33.

124. Ozaki A, Kitano M, Furusawa N, Yamaguchi H, Kuroda K, Endo G. Genotoxicity of Gardenia yellow and its components. Food Chem Toxicol. 2002; 40(11): 1603-10.

125. Gao LN, Zhang $Y$, Cui $Y L$, Yan K. Evaluation of genipin on human cytochrome P450 isoenzymes and P-glycoprotein in vitro. Fitoterapia 2014; 98(1): 130-6.

126. Potdar D, Hirwani RR, Dhulap S. Phyto-chemical and pharmacological applications of Berberis aristata. Fitoterapia 2012; 83(5): 817-30.

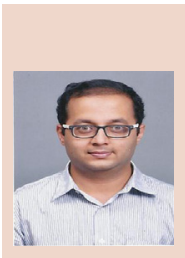

\section{ABOUT AUTHOR}

Mr. Rohan Sharadanand Phatak: Presently working as Junior Research Officer in Krishna Institute of Medical Sciences University, Karad. His qualification is M. Pharma specialized in Pharmacognosy. His interest in antioxidant studies of different medicinal plants. He is still working in assisting for editing medical research journal "Journal of Krishna Institute of Medical Sciences" (www.jkimsu.com). He has recently published 8 research papers and continues working on antioxidant studies in various medicinal plants. He has experience to scrutinize in the intellectual property of medicinal plants. 